\title{
Taxonomic revision of Dasydorylas Skevington, 2001 (Diptera, Pipunculidae) in the Middle East
}

\author{
Behnam Motamedinia ${ }^{\text {Corresp., } 1,2}{ }^{,}$Jeffrey Skevington ${ }^{1,3}$, Scott Kelso $^{1}$ \\ ${ }^{1}$ Canadian National Collection of Insects, Arachnids and Nematodes, Agriculture and Agri-Food Canada, Ottawa, Ontario, Canada \\ 2 Plant Protection Research Department, South Agricultural and Natural Resources Research and Education Center, AREEO, Birjand, Iran \\ 3 Carleton University, Biology Department, Ottawa, Ontario, Canada \\ Corresponding Author: Behnam Motamedinia \\ Email address: bmoetamedi@yahoo.com
}

Species of the distinctive and cosmopolitan genus Dasydorylas Skevington, 2001 in the Middle East are revised. Seven species are documented, and three new species, Dasydorylas dactylos sp. nov., Dasydorylas forcipus sp. nov. and Dasydorylas parazardouei sp.nov., are described, and one synonym, Dasydorylas derafshani Motamedinia \& Kehlmaier, 2017, syn. nov. is proposed, based on sequence information from the mitochondrial COI barcoding gene and morphological parameters. Diagnoses, illustrations and distributional data are provided for all studied species. Descriptions of new species as well as an identification key to all known species in the Middle East are also provided. 
1 Taxonomic revision of Dasydorylas Skevington, 2001 (Diptera, Pipunculidae) in the Middle East

2

3 Behnam Motamedinia ${ }^{1,2}$, Jeffrey H. Skevington ${ }^{1,3}$, Scott Kelso ${ }^{1}$

4

$5{ }^{1}$ Canadian National Collection of Insects, Arachnids and Nematodes, Agriculture and Agri-Food 6 Canada, 960 Carling Avenue, Ottawa, ON, K1A 0C6, Canada

$7 \quad 2$ Plant Protection Research Department, South Agricultural and Natural Resources Research and

8 Education Center, AREEO, Birjand, Iran

9 Corresponding Author: Behnam Motamedinia

10 Email address: Bmoetamedi@yahoo.com

$11{ }^{3}$ Carleton University, Biology Department, 207 Nesbitt Biology Building, 1125 Colonel By

12 Drive, Ottawa, ON K1S 5B6, Canada 
14

15 16

Abstract

Species of the distinctive and cosmopolitan genus Dasydorylas Skevington, 2001 in the Middle East are revised. Seven species are documented, and three new species, Dasydorylas dactylos sp. nov., Dasydorylas forcipus sp. nov. and Dasydorylas parazardouei sp.nov., are described, and one synonym, Dasydorylas derafshani Motamedinia \& Kehlmaier, 2017, syn. nov. is proposed, based on sequence information from the mitochondrial COI barcoding gene and morphological parameters. Diagnoses, illustrations and distributional data are provided for all studied species. Descriptions of new species as well as an identification key to all known species in the Middle East are also provided.

Keywords

Asia, big-headed flies, COI, distribution map, DNA barcoding, identification key, mini barcode strategy

Introduction

Dasydorylas Skevington, 2001 are mid-sized (2.8-4.5 mm) big-headed flies placed within the tribe Eudorylini (Diptera: Pipunculidae: Pipunculinae). The first Dasydorylas species were described by Becker in 1897 as Pipunculus horridus and Pipunculus discoidalis. Perkins (1905), Becker (1908), Banks (1915), Hardy (1950, 1954, 1961, 1968, 1972), Koizumi (1959) and Kuznetzov (1994) described additional Dasydorylas species under the genera Pipunculus, Dorilas and Eudorylas. Dasydorylas was coined during a comprehensive phylogenetic study of world Eudorylini published by Skevington \& Yeates in 2001. Although Skevington and Yeates (2001) found that Dasydorylas is sister to a large clade including Amazunculus Rafael, 1986, Elmohardyia Rafael, 1987, Basileunculus Rafael, 1987, Allomethus Hardy, 1943 and Claraeola Aczél, 1940, our preliminary unpublished target enrichment analysis suggests that the genus is sister to Claraeola Aczél, 1940. The genus group can be best distinguished by a combination of the following morphological characters: pterostigma present, notopleuron often with dense bush of long setae, femora often with posterdorsal row of long and back setae, scutellum with an apical setae, tergite 1 with distinct setae laterally, sternite 3-5 often with posterior setae, syntergosternite 8 with membranous area of medium size, male terminalia with ejaculatory apodeme funnel-shaped (Skevington \& Yeates, 2001). There are few biological data available for 
43 the genus Dasydorylas. Dasydorylas eucalypti (Perkins, 1905) (type species) and D. comitans

44 (Perkins, 1905) were reared from Cicadellidae nymphs (Hemiptera: Auchenorrhyncha).

45 46

Dasydorylas is a cosmopolitan genus with 32 described species occurring in the Afrotropical (nine species), Palaearctic (nine species), Australasian and/or Oriental (nine species) and the Nearctic and/or Neotropical regions (five species) (Skevington \& Yeates, 2001; Kehlmaier, 2005a; Kehlmaier, 2005b; Földvári, 2013; Motamedinia et al., 2017a; Motamedinia et al., 2017b; Skevington, 2019, unpublished data). An identification key to Palaearctic and Afrotropical species was provided by Kehlmaier (2005a) and Földvári (2013).

Despite its large size $\left(7,207,575 \mathrm{~km}^{2}\right)$ and special geographical position, the Middle East [here defined to include Bahrain, Cyprus, Iran, Iraq, Israel, Jordan, Kuwait, Lebanon, Oman, Palestine, Qatar, Saudi Arabia, Syria, Turkey, United Arab Emirates, and Yemen] Dasydorylas diversity is largely unknown and only three species (D. discoidalis (Becker, 1897); D. gradus Kehlmaier, 2005; D. zardouei Motamedinia \& Kehlmaier, 2017) have been reported from this poorly studied region.

In this work we revise the genus Dasydorylas in the Middle East and describe two new species based on morphological characteristics and sequence data from the mitochondrial COI barcoding region. We also provide an identification key and distribution map to the Middle Eastern Dasydorylas species.

Materials and Methods

\section{Specimen collection and morphological study}

The specimens examined were collected by Malaise trap and sweep net from Iran, Israel, the United Arab Emirates and Yemen. Specimens captured in traps were collected into 60\%-90\% ethanol, dehydrated into absolute ethanol and then Critical-Point Dried (CPD) and pointed. The Dasydorylas specimens examined for this study belong to the following collections: CNC (Canadian National Collection of Insects, Arachnids and Nematodes), HMIM (Hayk Mirzayans Insect Museum, Insect Taxonomy Research Department, Iranian Research Institute of Plant Protection, Tehran, Iran) and TAU (Tel Aviv University, Israel).

For several species, characters for accurate identification have only been found in the male genitalia. We applied a morphological species concept for our work, essentially looking for discrete differences in the male genitalia that were invariant between specimens examined. Some 
73 external characters were found to support the species concepts, but concepts were mostly

74 supported empirically by DNA barcode data (i.e. significant barcode gaps were found between

75 species and within species variation was usually than $2 \%$ ). No cryptic species were discovered

76 based on DNA that could not be recognized morphologically (i.e. all BOLD BIN's were

77 supported by both morphology and DNA). Male genitalia were stored in microvials containing

78 glycerin after clearing in hot lactic acid $(85 \%)$ at $100^{\circ} \mathrm{C}$ for $30-240$ minutes. For some darker

79 genitalia, terminalia were treated with $10 \% \mathrm{KOH}$ at $100^{\circ} \mathrm{C}$ for $10-30$ minutes then neutralized in

80 glacial acetic acid for 5 minutes. Females were included in the type series if DNA data

81 corroborated their linkage with sequenced males. All specimens are labeled with a unique

82 reference number from the CNC database (e.g., Jeff_Skevington_Specimen 12345 and

83 CNC_Diptera12345, abbreviated as JSS12345 and CNCD12345 respectively) and can be

84 accessed at https://cnc.agr.gc.ca/. SimpleMappr (Shorthouse, 2010) was used to create the

85 species distribution map.

86 Photographic equipment used for external characters was a Leica DFC450 module fitted on a

87 Leica M205C stereomicroscope and 0.6x lens. Image series comprising 15-20 focal planes were

88 merged to produce a single image with increased depth of field using the image-stacking

89 software ZereneStacker (Littlefield, 2018). Dissected material was mounted in glycerin and

90 photographed with a Leica DM5500B microscope equipped with a Leica DMC4500 module

91 connected to a personal computer running the Leica Application Suite software

92 (https://www.leica-microsystems.com), which includes an Auto-Montage module that combines

93 multiple layers of photographs into a single fully focused image. Photos were edited and

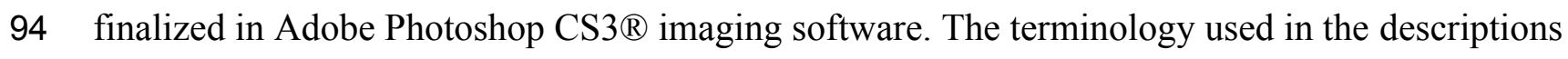

95 is based on Skevington (2002) and Kehlmaier (2005a) with the following abbreviations being

96 used throughout the paper:

$97 \mathrm{LF}: \mathrm{WF}=$ ratio of length of flagellum to its width.

98 LW:MWW = ratio of length of wing to maximum width of wing.

99 LS:LTC = ratio of length of pterostigma to length of third costal segment.

100 LTC:LFC = ratio of length of third costal segment to length of fourth costal segment.

101 LT35:WT5 = ratio of length of tergites 3-5 to maximum width of tergite 5.

102 WT5:LT5 $=$ ratio of width of tergite 5 to its length.

103 T5R:T5L = ratio of length of right margin of tergite 5 to length of its left margin. 
104 LT35:WS8 = ratio of length of tergites 3-5 to width of syntergosternite 8 .

105 LS8:HS8 = ratio of length syntergosternite 8 to its height.

106 MLE:MWE = ratio of maximum length of epandrium to its maximum width (viewed dorsally).

107 LP:LB = ratio of length of piercer to length of base (viewed laterally).

108 LDP:LPP = ratio of length of distal part of piercer to length of its proximal part (viewed 109 laterally).

110

111 DNA extraction, PCR amplification and sequencing

112 Total genomic DNA was non-destructively extracted from 2 legs, or whole specimens using the 113 DNeasy Tissue kit (Qiagen Inc., Santa Clara, CA, USA) following the manufacturer's protocol. 114 Following extraction, specimens were critical-point dried and deposited as vouchers in all 115 aforementioned collections.

116 For DNA barcoding, a $658 \mathrm{bp}$ fragment of the 5' end of the mitochondrial coding gene

117 cytochrome oxidase subunit I (COI) was sequenced followed protocols published Gibson et al.

118 (2011). In some cases, initial attempts to amplify the full COI barcode failed, presumably due to 119 the degradation of the DNA. In these cases, a novel COI mini-barcode protocol was employed 120 (Young et al. in prep.) in order to amplify a 214 bp fragment (COI-Fx-C), located at the 3'-end of 121 the COI barcode region, for species identification. In the case of putative new species, efforts 122 were made to amplify the $5^{\prime}$ and middle COI mini-barcode fragments (COI-Fx-A and COI-Fx-B 123 respectively) that, when combined, provide a complete COI barcode sequence. Oligonucleotides 124 (primers) used in this study are listed in Table 1. Sanger Sequencing was performed at CNC. 125 All sequence chromatograms were edited and contigs formed using Sequencher 5.4.6 (Gene 126 Codes Corp., Ann Arbor, MI, USA). Resulting contigs were hand-aligned using Mesquite 3.6 127 (Maddison and Maddison, 2018). Uncorrected pairwise genetic distances (p-distance) were 128 calculated with Mega7 (Kumar et al. 2016). Sequence accession numbers issued by GenBank 129 (GB) are provided for each species in the material examined sections.

130 The electronic version of this article in Portable Document Format (PDF) will represent a 131 published work according to the International Commission on Zoological Nomenclature (ICZN), 132 and hence the new names contained in the electronic version are effectively published under that 133 Code from the electronic edition alone. This published work and the nomenclatural acts it 134 contains have been registered in ZooBank, the online registration system for the ICZN. The 
135 ZooBank LSIDs (Life Science Identifiers) can be resolved and the associated information viewed 136 through any standard web browser by appending the LSID to the prefix http://zoobank.org/. The 137 LSID for this publication is: urn:1sid:zoobank.org:pub:A19B5B2E-817F-463C-A217-

138 869C44C25C0A. The online version of this work is archived and available from the following 139 digital repositories: PeerJ, PubMed Central and CLOCKSS."

140 Results

141 Taxonomy

142 Genus Dasydorylas Skevington, 2001

143 Type species: Pipunculus eucalypti Perkins, 1905

144 Diagnosis

145 Small to medium bodied flies; body length 2.8-4.5 mm; wing length 2.7-5.2 mm; pedicel with 146 3-6 upper and 1-4 lower bristles; flagellum silver gray to brownish pollinose; vertex lacking 147 pollinosity bearing an elevated equilateral ocellar triangle; postpronotal lobe often with 4-7 long 148 setae along upper margin; scutellum with a fringe of 6-16 setae; front femur usually with rows of 149 ventral spines; front and mid tibiae with short distal spines; pterostigma present; crossvein r-m 150 reaches dm at or after one third of the cells length; abdomen ovate, ground color dark (in some 151 specimens with posterolateral markings of gray pollinosity); tergite 1 with 3-16 long bristles 152 laterally; hypandrium often with cluster of anteromedial setae; phallus trifid; phallic guide strong 153 (some species with medium to large spines); ejaculatory apodeme usually funnel-shaped; sperm 154 pump usually vase-shaped, with lateral flange around entire upper surface.

\section{Biology}

156 Unknown except D. eucalypti and D. comitans, which were reared from Cicadellidae nymphs 157 (Perkins, 1905).

158 Distribution

159 Afrotropical (Botswana, Burundi, Congo (Democratic Republic), Kenya, Madagascar, Malawi, 160 Morocco, Namibia, Tanzania, Uganda, United Arab Emirates, Zimbabwe); Australasia 161 (Australia, Papua New Guinea); Nearctic (Mexico, USA); Neotropical (Argentina, Brazil, Costa 162 Rica, Nicaragua); Oriental (India, Laos, Myanmar, Philippines, Taiwan, Thailand, Vietnam); 163 Palaearctic (Austria, Belgium, Bulgaria, Canary Islands, China, Croatia, Czech Republic, 164 Denmark, France, Germany, Great Britain, Hungary, Iran, Israel, Italy, Japan, Latvia, 
165 Netherlands, North Korea, Portugal, Romania, Russia, Slovakia, Spain, Switzerland (Kehlmaier, 166 2005a; Kehlmaier, 2005b; Kehlmaier, Gibbs \& Withers, 2019; Motamedinia et al., 2017a;

167 Motamedinia et al., 2017b; Skevington, 2019, unpublished data).

168 Key to males of Dasydorylas species in the Middle East

169 1-Compound eyes meeting each other (Figs 1A-1B) ...3

170 - Compound eyes converging but not meeting each other (Figs 2A-2B)...2

171 2- Phallic guide with 8 downward spines (Fig. 3C); base of surstyli longer than wide (Figs 3A172 3B)... Dasydorylas discoidalis (Becker)

173 - Phallic guide with 6-7 downward spines, base of surstyli as long as wide (Figs 4A-4B)...

174 Dasydorylas dactylos Motamedinia \& Skevington

175 3-Abdominal tergite 1 with 13-16 strong bristles laterally (Figs 5A-5B); phallic guide without 176 spine (Figs 6D-6E)...Dasydorylas horridus (Becker)

177 - Abdominal tergite 1 with fewer than 13 bristles laterally; phallic guide with spine (Figs 7D, 178 8D)...4

179 4- Phallic guide with 13-14 long spines (Figs 8D-8E)...Dasydorylas gradus Kehlmaier 180 - Phallic guide with two spines...5

181 5- Hind femur with weak wrinkles anteriorly (Fig. 9A); inner side of surstyli almost rounded in 182 lateral view (Figs 7C-7D)...Dasydorylas forcipus Motamedinia \& Skevington

183 - Hind femur without anterior wrinkles, inner side of surstyli not as above in lateral view...6

184 6-Abdomen brown (Fig. 1A); hypandrium with hypandrial apodeme (Fig. 10B)...Dasydorylas 185 parazardouei Motamedinia \& Skevington

186 - Abdomen dark, hypandrium without hypandrial apodeme (Fig. 11B)...Dasydorylas zardouei

187 Motamedinia \& Kehlmaier

188

189 Dasydorylas dactylos Motamedinia \& Skevington sp. nov.

190 Figs $4 \mathrm{~A}-4 \mathrm{E}$

191 urn:Isid:zoobank.org:act:BCE6B5FC-5C25-49C4-8473-F6D662DCE8CF

192 Materials examined

193 Israel: holotype: male, Neot Semadar, 30.0333, 35.0166, 4.XII.1995, leg. A. Freidberg, 194 JSS50777, GB: MN520769, TAU.

195 Diagnosis 
196 This species can be recognized by the long tapering flagellum; separated compound eyes in 197 males; ocellar triangle divided by a median groove; apical finger-like process in surstyli; 6-7 198 downward spines on either side of phallic guide (Figs 4D-4E).

\section{Description}

200 Body length. $3.3 \mathrm{~mm}$ (excluding antennae).

201 Head. Face dark, silver-gray pollinose. Scape, pedicel and arista dark; pedicel with 1-2 short 202 upper bristles and two short lower bristle; flagellum light brown, long tapering (LF:WF = 2.4). 203 Eyes converging but not meeting and separated by less than diameter of frontal facets. Frons 204 dark, silver-gray pollinose; vertex dark with elevated equilateral ocellar triangle divided by a

205

206

207

208

209

210

211

212

213

214

215

216

217

218

219

220

221

222

223

224

225

226 median groove, lacking pollinosity, shining black; occiput dark, gray pollinose. Thorax. Pleura, prescutum, scutum and scutellum dark. Pleura gray pollinose. Postpronotal lobe pale, gray pollinose and with 10-12 postpronotal setae along upper margin. Prescutum and scutum gray pollinose, with two uniseriate dorsocentral rows of setae and some supra-alar setae. Scutellum gray-brown pollinose, with a fringe of up to 16 long dark hairs (up to $0.18 \mathrm{~mm}$ ) and with numerous shorter hairs on its dorsal surface. Subscutellum gray-brown pollinose. Wing. Length: $3.5 \mathrm{~mm}$. LW:MWW = 3.3. Wing almost entirely covered with microtrichia. Pterostigma brown and complete (LS:LTC = 1.0, LTC:LFC = 1.1). $\mathrm{M}_{1}$ straight. Length of halter: $0.5 \mathrm{~mm}$; base dark, stem narrowly white and knob yellow; base and stem somewhat gray pollinose. Legs. Fore and mid coxae dark brown, hind coxa dark, gray pollinose; mid coxa with 4-5 brown anterior bristles. Trochanters dark brown, gray pollinose; hind trochanter with 1-2 long lateral bristles. Femora dark brown, distinctly yellow at apex, gray pollinose. All femora bearing two rows of dark, smaller, peg-like anteroventral spines on apical one third; hind femur swollen in middle. Tibiae yellow, ventrally darkened in apical half, with three rows of yellow setae on anterior and posterior side, without apical spines. Tarsi yellow, brown pollinose. Distitarsi dark. Pulvilli longer than distitarsi. Abdomen. Ground color dark. Tergite 1 with 8-10 light brown lateral bristles. Tergites 1-5 gray pollinose with scattered light brown bristles. Syntergosternite 8 dark brown, brown pollinose, without dorsal depression on side of right surstylus. Membranous area vertically directed, broader in upper half, occupying about a third of the width of syntergosternite 8. Genitalia. Genital capsule in dorsal view: epandrium dark brown, brown pollinose and longer than wide (MLE:MWE =1.1). Surstyli brown, brown pollinose and symmetrical. Both surstyli have a broad and short base with an inner, long apical fingerlike process (Fig. 4A). Tips of outer 
227 projection slightly bent inward. Genital capsule in ventral view: gonopods minute and 228 symmetrical (Fig. 4B). Genital capsule in lateral view: both surstyli in basal half broad, in apical 229 half narrowed to form a finger-like process, outer one is straight and inner one bent slightly 230 towards the sternite (Figs 4D-4E). Phallus trifid, straight and long, phallic guide of medium 231 length, broad with fingerlike process at apex, bow-like bent towards surstyli, on either side with 232 6-7 downwards directed long spines at its apex (Figs 4D-4E). Ejaculatory apodeme funnel233 shaped (Fig. 4C).

234 Distribution

235 Israel (Fig. 12).

236 Etymology

237 The species name is derived from Greek "dactylos" (finger) referring to the shape of the surstyli. 238 Molecular variation

239 Based on uncorrected pairwise genetic distances (p-distance), this species is close to $D$.

240 discoidalis, differing by $6.9 \%$ (Table 2 ).

241

242

Dasydorylas discoidalis (Becker, 1897)

243 Figs 2A-2B, 3A-3E

244 Pipunculus discoidalis Becker, 1897: 46.

245 Dasydorylas derafshani Motamedinia \& Kehlmaier, 2017; syn. nov.

246 Materials examined

247 United Arab Emirates: two males, Abu Dhabi, Al Wathba Wetland Reserve, 24.254303, 248 54.610875, II.2015, leg. A. Saji \& A. van Harten, Malaise trap, CNCDD470470, CNCD470534, 249 CNCD; six males, four females, III.2015, leg. A. Saji \& A. van Harten, Malaise trap, 250 CNCD470632, GB: MN520770, CNCD470633, CNCD470635, CNCD470647, GB: MN520764, 251 CNCD470655, CNCD470658, CNCD470659, CNCD470661, CNCD470696, CNCD470700,

252 CNCD; four males, seven females, IV.2015, leg. A. Saji \& A. van Harten, Malaise trap, 253 CNCD470809, GB: MN520762, CNCD470813, CNCD470814, CNCD470815, CNCD470818, 254 CNCD470820, CNCD470822, CNCD470826, CNCD470836, CNCD470843, CNCD470848, 255 CNC. Israel: one male, Arava Valley, nr Hazeva, Shizaf Nature Reserve, side channel of Wadi 256 Shahak, 30.7500, 35.2500, -116m, 24.III.1995, leg. M. E. Irwin, Malaise trap, JSS50852, TAU; 257 one male, Enot Zuqim south to gate, 30.4833, 35.1500, 26.IV.2006, leg. L. Friedman, 
258 Jeff_Skevington_Speimen50829, TAU; one male, Nahal Deragot, 31.3000, 35.0833, 790m, 259 28.II.1994, leg. A. Freidberg, JSS50851, TAU. Iran: 1ð̋, Khuzestan, Shush, 32.066667, 48.2333, 260 68m, 11.III-10.V.2015, leg. E. Gilasian, Malaise trap, JSS52200, GB: MN520767, HMIM; one 261 female, Sistan \& Balochestan, Rask, 26.266667, 61.416667, 139m, 10.VI-14.VII.2016, leg. M. 262 Ghaforimoghadam, Malaise trap, JSS52140, CNC; one male, Zabol, 31.116667, 61.466667, 263 481m, 15.VI.2016, leg. H. Derafshan, sweeping, JSS51901, CNC; one female, 6.VI.2016, leg. H. 264 Derafshan, sweeping, JSS51873, CNC.

\section{Diagnosis}

266 This species can be recognized by separated compound eyes in males (converging but not 267 meeting) (Figs 2A-2B); long posterior setal fringe of the scutellum and evenly distributed setae 268 on the abdominal tergites; phallic guide with eight downward directed spines at the apex (Figs $2693 \mathrm{C}-3 \mathrm{D})$; ovipositor with the largely swollen sternite 8.

\section{Distribution}

271 Iran, Israel, Russia, United Arab Emirates (Kehlmaier, 2005a; Motamedinia et al., 2017b;

272 Skevington, 2019, unpublished data) (Fig. 12 shows Middle Eastern distribution only).

273 Notes

274 Dasydorylas discoidalis was described by Becker (1897) based on a female specimen. Kehlamier 275 re-described the female in 2005(a).

\section{Molecular variation}

277 Sequence data for $D$. discoidalis (1 female) and $D$. derafshani (3 males) show they are 278 conspecific (0.0-3.0\% uncorrected pairwise intraspecific difference - see Table 2). Based on 279 uncorrected pairwise genetic distances (p-distance), the nearest species to D. discoidalis is $D$. 280 dactylus with a COI distance of $6.9 \%$ (Table 2).

281 Nomenclatural changes

282 Dasydorylas derafshani Motamedinia \& Kehlmaier, 2017 is hereby treated as a new synonym of 283 D. discoidalis Becker (1897) based on the molecular evidence presented above.

\section{Dasydorylas forcipus Motamedinia \& Skevington sp. nov.}

286 Figs 7A-7D, 9A-9B

287 urn:1sid:zoobank.org:act:0F5D0097-4983-41FB-B35E-E71AB00C56C0 
289 Israel: holotype : male, Nahal Qana Reserve, 32.1333, 35.0333, 120m, 9.VII.2007, leg. A.

290 Freidberg, JSS51680, TAU.

291 Diagnosis

292 Hind femur with some weak wrinkles anteriorly (Figs 9A-9B); abdomen dark brown; phallus

293 trifid, shorter than phallic guide; phallic guide with two spines (Figs 7B-7D).

294 Description

295 Body length. 2.9-3.0 mm (excluding antennae).

296 Head. Face dark, silver-gray pollinose. Scape dark, pedicel brown with two short upper bristles;

297 flagellum dark brown, short tapering and gray pollinose $(\mathrm{LF}: \mathrm{WF}=1.7)$; arista dark with

298 thickened base. Eyes meeting for 5-6 facets. Frons dark, silver-gray pollinose; vertex dark,

299 lacking pollinosity, shining black; occiput dark, gray pollinose. Thorax. Pleura, prescutum,

300 scutum and scutellum dark with a mixture of gray and brown pollinosity. Postpronotal lobe pale,

301 gray pollinose and with 4-6 short postpronotal setae along upper margin. Prescutum and scutum

302 with two uniseriate dorsocentral rows of setae and patches of supra-alar setae. Scutellum gray to

303 brown pollinose, with a fringe of up to 12 short brown setae (up to $0.08 \mathrm{~mm}$ ). Subscutellum with

304 a mixture of gray and brown pollinosity. Wing. Length: 3.0-3.1 mm. LW:MWW = 2.7-2.8.

305 Wing almost entirely covered with microtrichia. Pterostigma brown and complete (LS:LTC =

306 1.0, LTC:LFC = 1.18). $\mathrm{M}_{1}$ straight. Length of halter: $0.4 \mathrm{~mm}$; base dark, half of stem pale and

307 knob brown; base and stem somewhat gray pollinose. Legs. Coxae dark, gray pollinose. Mid

308 coxa and mid trochanter with two dark anterior bristles. Trochanters dark, partly gray pollinose.

309 Femora dark, gray pollinose. Fore and mid femora bearing two rows of dark, small, peg-like

310 anteroventral spines on apical one third. Hind femur with some weak wrinkles anteriorly. Tibiae

311 dark, sometimes apices pale, gray pollinose, with three rows of setae on anterior and posterior

312 side. Hind tibia with some weak wrinkles midanteriorly. Tarsi dark, gray pollinose, with some

313 brown setae dorsally. Hind basitarsus as long as other tarsomeres. Distitarsi dark, longer than

314 pulvilli. Abdomen. Ground color dark brown. Tergite 1 with five to six lateral bristles. Tergites

315 with a mixture of gray and brown pollinosity. Syntergosternite 8 dark brown, brown pollinose.

316 Membranous area large, roughly triangular, ventrocaudally directed. Genitalia. Genital capsule

317 in dorsal view: epandrium dark brown, brown pollinose and wider than long (MLE:MWE $=0.8$ ).

318 Surstyli brown, pale at apices, brown pollinose, more reduced in apices, rather symmetrical. Both

319 surstyli with a blocky base and a broad finger-like projection at its apical inner corner, bent 
320 outward distally by $90^{\circ}$ (Fig. 7A). Genital capsule in ventral view: gonopods minute and 321 symmetrical, with elongated regions of distinctly stronger sclerotization (Fig. 7B). Genital 322 capsule in lateral view: epandrium without projecting lobe on either side. Both surstyli in basal 323 half broad, in apical half narrowed to form a finger-like process, which is bent towards the 324 sternite, inner side of surstyli almost rounded (Figs 7C-7D). Phallus trifid, straight and short; 325 phallic guide bow-like bent towards surstyli, with two dorsolateral spines at the end of basal half 326 on either side (Figs 7C-7D). Ejaculatory apodeme funnel-shaped (Fig. 7B).

\section{Distribution}

328 Israel (Fig. 12).

329 Etymology

330 The species name is derived from Latin forceps (tongs) referring to the shape of surstyli in the 331 male genitalia.

332

333 Dasydorylas gradus Kehlmaier, 2005

334 Figs $8 \mathrm{~A}-8 \mathrm{E}$

\section{Materials examined}

336 Israel: one male, Nahal Namir, 33.0833, 35.2000, 2.XI.1998, leg. S. Alfi, JSS50771, GB:

337 MN520768, TAU; one female, NabiHazuri, 33.2500, 35.7333, 790m, 18.X.2009, leg. A.

338 Freidberg, JSS50850, GB: MN520763, TAU; Cyprus: one male, Kyrenia, 35.3477, 33.1504, 1-

339 8.X.2017, leg. O. Ozden, Malaise trap, JSS52303, GB: MN520765, CNC; one male, 5-

340 12.XI.2017, leg. O. Ozden, Malaise trap, JSS52307, CNC.

\section{Diagnosis}

342 Hind tibia with a wrinkled indentation midanteriorly, bearing one strong, dark bristle; abdominal

343 tergite 1 with up to seven dark lateral bristles, becoming shorter towards the center of the tergite;

344 phallic guide bow-like bent towards dorsal surface of genital capsule (in lateral view), with 13 to 34514 long, straight spines, pointing upwards into various directions (Figs 8D-8E).

\section{Distribution}

347 Cyprus, Israel, Turkey, (Kehlmaier, 2005b; Kehlmaier, Gibbs \& Withers, 2019; Skevington, 348 2019, unpublished data) (Fig. 12).

\section{Molecular variation}


350 Based on uncorrected pairwise genetic distances (p-distance), this species is close to D. dactylus 351 differing by $8.2 \%$ (Table 2). Intraspecific genetic distance within the Israeli specimens is $1.3 \%$ 352 and within Israeli and Cyprus specimens ranges from $0.4 \%$ to $1.7 \%$ (Table 2).

353

354

355

356

357

358

359

360

361

362

363

364

365

366

367

368

369

370

371

372

373

374

375

376

377

378

379

380

381

\section{Dasydorylas horridus (Becker, 1897)}

Figs $5 \mathrm{~A}-5 \mathrm{~B}, 6 \mathrm{~A}-6 \mathrm{E}$

Pipunculus horridus Becker1897: 41.

\section{Materials examined}

Iran: one male, Taleghan, Alborz, 36.166667, 50.7500, leg. A. Jabari, Malaise trap, JSS52204, GB: MN520766, CNC.

\section{Diagnosis}

Abdominal tergites densely covered with rather long setae; tergite 1 with about 13-16 strong and dark lateral bristles of different length; surstyli sickle shaped; phallic guide strictly bow-like bent towards surstyli, without spines (Figs 6D-6E); phallus trifid; ejaculatory apodeme funnel-shaped (Fig. 6C).

\section{Distribution}

Austria, Belgium, Bulgaria, Croatia, Czech Republic, France, Germany, Great Britain, Hungary, Iran, Italy, Latvia, Netherlands, Poland, Slovakia, Slovenia, Spain, Switzerland and Yugoslavia. (Kehlmaier, 2005a; Kehlmaier \& Jahromi, 2014; Skevington, 2019, unpublished data) (Fig. 12 shows Middle Eastern distribution only).

\section{Molecular variation}

Based on uncorrected pairwise genetic distances (p-distance), this species is close to D. gradus differing by $9.9-10.8 \%$ (Table 2 ).

\section{Dasydorylas parazardouei Motamedinia \& Skevington sp. nov.}

Figs $1 \mathrm{~A}-1 \mathrm{~B}, 10 \mathrm{~A}-10 \mathrm{E}, 13$

urn:1sid:zoobank.org:act:17ECF386-9A41-43F6-9B20-42EEF0E01600

\section{Materials examined}

United Arab Emirates: holotype: male, Wadi Wurayah, 25.2400, 56.1700, 25.III.2007, sweep net, leg. F. Menzel \& A. Stark, CNCD175301, GB: MN520761, CNC.

Paratypes: one male, one female, same data as holotype, CNCD175302, CNCD175303, GB: MN520771, CNC. 


\section{Diagnosis}

383 Abdomen brown (Fig. 1A); frons with a median keel in upper half; tergite 1 with three strong 384 lateral bristles, arranged in one row; hypandrium distinctly bulging in underside (Fig. 10B);

385 phallic guide strong, bow-like bent towards surstyli with two spines on each side (Figs 10D386 10E).

387 Description

388 Male

389 Body length. 3.1-3.5 mm (excluding antennae). Head. Face dark, silver-gray pollinose. Frons 390 brown, with a median keel in upper half. Pedicel brown with three short upper bristles and one 391 long lower bristle; flagellum brown, short tapering (LF:WF $=2.1-2.2)$; arista brown. Eyes 392 meeting for seventeen facets (Fig. 1B). Vertex and occiput brown. Pleura, prescutum, scutum 393 and scutellum brown. Pleura gray pollinose. Postpronotal lobe pale, gray pollinose and with 2-3 394 postpronotal setae along upper margin. Scutum gray pollinose, with patches of supra-alar setae.

395 Scutellum gray pollinose, with a fringe of up to 10 dark setae. Subscutellum gray pollinose, 396 Wing length: 3.1-3.3 mm. LW:MWW = 3.0-3.1. Wing almost entirely covered with 397 microtrichia. Pterostigma brown and complete (LS:LTC $=1.0$, LTC:LFC = 1.1. Halter length:

$3980.5 \mathrm{~mm}$. Base dark, stem narrowly white and knob brown. Legs. All femora bearing two rows of 399 dark anteroventral spines on apical one third. Tibiae with three rows of setae on anterior and 400 posterior side, without apical spines. Hind tibia with some weak wrinkles midanteriorly. Tarsi 401 brown and paler than tibiae, pulvilli smaller than distitarsi. Abdomen. Ground color brown.

402 Tergite 1 gray pollinose with three strong lateral bristles, arranged in one row. Tergites 1-5 with 403 brown setae. Syntergosternite 8 brown, without dorsal depression on side of right surstylus, as 404 long as high (LS8:HS8 = 1.0). Membranous area vertically directed, broader in upper half, 405 occupying about a third of the width of syntergosternite 8. Epandrium dark brown, pollinose 406 except left edge. Genitalia. Genital capsule in dorsal view: surstyli brown, narrowly pale at 407 apices, brown pollinose and rather symmetrical. Both surstyli with a blocky base and a broad 408 finger-like projection at its apical inner corner, bent outward distally by $90^{\circ}$, base of right 409 surstylus slightly wider than left surstylus. Genital capsule in lateral view: both surstyli in basal 410 half broad, in apical half narrowed to form a finger-like process, which is bent towards the 411 sternite by $90^{\circ}$ (Fig. 10D-10E). Phallus straight and slender, with one or two ejaculatory ducts, 412 phallic guide strong, bow-like bent towards surstyli (Figs 10D-10E), with two dorsolateral 
413 spines at the end of basal half on either side (Figs 10D-10E). Ejaculatory apodeme funnel414 shaped (Fig. 10C). Genital capsule in ventral view: gonopods minute and symmetrical, with 415 elongated regions of distinctly stronger sclerotization (Fig. 10B).

\section{Female}

417 Scape dark, with one upper short bristle. Pedicel with two short upper bristles and one long lower 418 bristle. Flagellum short tapering. LF:WF = 2.0-2.2. Eyes separated. Frons dark, lower half 419 silver-gray pollinose, otherwise shining. Frons anterior to ocellar triangle with median keels 420 narrowing in lower half and ending in a tubercle shortly before antenna. Lateral rows of setae 421 starting a bit before ocellar triangle and reaching down almost to tubercle. Postpronotal lobe 422 yellow, gray pollinose with some light brown bristles. Pleura, prescutum, scutum and scutellum 423 dark, gray pollinose. Femora with two small ventral rows of dark peg-like spine, restricted to 424 apical one thirds. Tergites 1-5 gray pollinose laterally, extending onto dorsal surface along 425 posterior margin. Tergites 2-5 with brown scattered bristles. Ovipositor light brown with some 426 gray pollinosity, base nearly rounded; piercer straight, longer than base. LP:LB = 1.5., LDP:LPP $427=3.3$ (Fig. 13).

\section{Etymology}

429 From para (=near) in Greek, referring to closely related to Das. zardouei (Motamedinia \& 430 Kehlmaier, 2017).

\section{Distribution}

432 United Arab Emirates (Fig. 12).

433 Notes

434 This species is related to Dasydorylas zardouei Motamedinia \& Kehlmaier, 2017, D.

435 holosericeus (Becker, 1897), re-described by Kehlmaier (2005a), D. roseri (Becker, 1897), re436 described by Kehlmaier (2005a), D. evanidus (Hardy, 1949), re-described by Földvári (2013), D. 437 orientalis (Koizumi, 1959), re-described by Kapoor et al. (1987) and also to D. antennalis 438 (Kapoor et al., 1987) from southern India. The male of Dasydorylas parazardouei differs from 439 these species by the shape of the surstylus in lateral view and a semicircular bulge-shaped of the 440 hypandrial apodeme in ventral view (Fig. 10B).

\section{Molecular variation}

442 We have sequence data for male and female specimens of this species that show they are 443 conspecific (0.00\% uncorrected pairwise intraspecific difference - see Table 2$)$. Based on 
444 uncorrected pairwise genetic distances (p-distance), this species is close to D. gradus, differing 445 by $9.9 \%$ (Table 2 ).

446

447 Dasydorylas zardouei Motamedinia \& Kehlmaier, 2017

448 Figs $11 \mathrm{~A}-11 \mathrm{E}$

449 Materials examined

450 Iran: one male, Kermanshah, Dodan, 35.000, 46.200, 1011m, 22.VII.2016, leg. M. Zardouei, 451 Malaise trap, JSS52209, CNC.

452 Diagnosis

453 Abdomen dark; tergite 1 with four to five strong lateral bristles, arranged in one row; both 454 surstyli with a blocky base and a broad finger-like projection at its apical inner corner, bent 455 outward distally by $90^{\circ}$ (Figs 11D-11E); base of right surstylus slightly wider than left surstylus 456 in dorsal view (Fig. 11A); phallic guide with two spines on each side (Figs 11D-11E).

\section{Distribution}

458 Iran (Motamedinia et al., 2017a; Skevington, 2019, unpublished data) (Fig. 12).

459 Notes

460 This species is closely related to D. holosericeus (Becker, 1897) and D. roseri (Becker, 1897), 461 both redescribed by Kehlmaier (2005a), the Afrotropical D. evanidus (Hardy, 1949), redescribed 462 by Földvári (2013), the Oriental D. orientalis (Koizumi, 1959), redescribed by Kapoor et al. 463 (1987), the southern Indian D. antennalis (Kapoor et al., 1987), described by Kapoor et al. 464 (1987) and D. parazardouei Motamedinia \& Skevington from the United Arab Emirates. The 465 males of $D$. zardouei differ from those of the other species by a different shape of gonopods in 466 ventral view and shape of surstyli in lateral view.

467

468 Discussion

469 Sexes are dimorphic and difficult to associate in Pipunculidae, so it is now routine to use DNA 470 barcodes to associate sexes (Skevington, Kehlmaier \& Ståhls, 2007; Motamedinia et al., 2017a; 471 Motamedinia, Skevington \& Kelso, 2019). Dasydorylas derafshani, which was described from 472 the male (Motamedinia et al. 2017), is associated here for the first time with D. discoidalis, 473 which was known only from females (Becker, 1897). Interspecific genetic distances within the 474 Middle Eastern Dasydorylas range from 6.9\% (D. discoidalis to D. dactylos) to 16.8\% (D. 
475 parazardouei to $D$.discoidalis), while intraspecific genetic distances range from $0 \%$ (within both 476 D. discoidalis and D. parazardouei from the United Arab Emirates) to 3\% (D. discoidalis from 477 the United Arab Emirates and Iran). Based on uncorrected pairwise genetic distances (p478 distance), D. dactylos is close to $D$. discoidalis, differing by $8.6 \%$ and $D$. gradus is most similar 479 to D. parazardouei differing by $9.9 \%$ (Table 2 ).

480

\section{Conclusions}

482 Prior to this study, the genus Dasydorylas included 32 worldwide species (Skevington, 2019, 483 unpublished data), with only four, D.discoidalis, D. gradus, D. horridus, D. zardouei present in 484 the Middle East. In this study we have extended the knowledge of this genus and described three 485 new species, Dasydorylas dactylos sp. nov., Dasydorylas forcipus sp. nov., Dasydorylas 486 parazardouei sp.nov. and synonymized $D$. derafshani with $D$. discoidalis.

487

\section{Acknowledgements}

489 We are grateful to C. Kehlmaier, A. Freidberg, N. Dorchin and A. van Harten for the loan of 490 specimens from Israel and the United Arab Emirates to the CNC. Special thanks to E. Rakhshani from Zabol University for his ongoing collaboration and support. We are indebted to $\mathrm{M}$.

Parchami-Araghi, E. Gilasian, M. Zardouei, M. Ghaforimoghadam, K. Ghahari and H. Derafshan 493 for collecting and providing the specimens from Iran.

494

495

496

497 498

499

500

501

502

503

504

505

References

Banks N. 1915. Notes and descriptions of Pipunculidae. Psyche 22:166-171.

Becker T. 1897. Dipterologische Studien V. Pipunculidae. Berliner Entomologische Zeitschrift 42:25-100.

Becker T. 1908. Dipteren der Kanarische Inseln. Mitteilungen aus dem Zoologischen Museum in Berlin 4:1-180.

Földvári M. 2013. Taxonomic revision of the Afrotropical species of the tribe Eudorylini (Diptera, Pipunculidae). Zootaxa 3656, 1-121. https://doi.org/10.11646/zootaxa.3656.1.1

Gibson JF, Kelso S, Jackson MD, Kits JH, Miranda GFG, Skevington JH. 2011. Diptera-Specific Polymerase Chain Reaction Amplification Primers of Use in Molecular Phylogenetic Research. Annals of the Entomological Society of America 104: 976-997. 
506 Hardy DE. 1950. Dorilaidae (Pipunculidae) (Diptera). Exploration Parc National Albert, I $507 \quad$ Mission GF de Witte 1933-1935 62:3-53.

508 Hardy DE. 1954. Neotropical Dorilaidae studies, Part III. Brazilian species and a key to the $509 \quad$ known species of Dorilas sens. lat. Boletim do Museu Nacional do Rio de Janeiro 123:1$510 \quad 60$.

511 Hardy DE. 1961. Bibionidae (Diptera Nematocera) and Dorilaidae (Pipunculidae: Diptera512 Cyclorrhapha). Exploration du Parc National de la Garamba, Mission H de Saeger $513 \quad 24: 111-180$.

514 Hardy DE. 1968. Bibionidae and Pipunculidae of the Philippines and Bismarck Islands (Diptera). $515 \quad$ Entomologiske Meddelelser 36:417-507.

516 Hardy DE. 1972. Studies on Oriental Pipunculidae (Diptera). Oriental Insects Supplement 2:1$517 \quad 76$.

518 Kapoor VC, Grewal JS, Sharma SK. 1987. Indian Pipunculids (Diptera: Pipunculidae). A

519 520

521

522

523

524

525

526

527

528

529

530

531

532

533

534 535 536 Comprehensive Monograph. Atlantic Publishers \& Distributors, New Delhi, India, 201 pp.

Kehlmaier C. 2005a. Taxonomic revision of European Eudorylini (Insecta, Diptera, Pipunculidae). Verhandlungen des Naturwissenschaftlichen Vereins in Hamburg 41:45353.

Kehlmaier C. 2005b. Taxonomic studies on Palaearctic and Oriental Eudorylini (Diptera: Pipunculidae), with the description of three new species. Zootaxa 1030:1-48.

Kehlmaier C, Majnon Jahromi B. 2015. On the presence of Pipunculidae (Diptera) in Iran. Studia dipterologica 21 (2014), 29-36.

Kehlmaier C, Gibbs D, Withers P. 2019. New records of big-headed flies (Diptera: Pipunculidae) from the Mediterranean Basin. Bonn zoological Bulletin 68 (1): 31-60. https://doi.org/10.20363/BZB-2019.68.1.031.

Koizumi K. 1959. On four dorilaid parasites of the green rice leafhopper, Nephotettix cincticeps Uhler (Diptera). Scientific Reports of the Faculty of Agriculture Okayama University 13:37-45.

Kuznetzov SY. 1994. Short notes on synonymy and nomenclature of Pipunculidae (Diptera). Dipterological Research 5:105.

Littlefield R. 2018. Zerene Stacker. http://zerenesystems.com/cms/stacker. 
537 Maddison WP, Maddison DR. 2018. Mesquite: a modular system for evolutionary analysis.

538 Version 3.51. Available from http://www.mesquiteproject.org.

539 Motamedinia B, Kehlmaier C, Mokhtari A, Rakhshani E, Gilasian E. 2017a The genus

540 Dasydorylas Skevington, 2001 in Iran with the description of two new species (Diptera:

541 Pipunculidae). The European Journal of Taxonomy 362, 1-13.

542 Motamedinia B, Mokhtari A, Rakhshani E, Gilasian E. 2017b. Review of Eudorylini (Diptera,

543 Pipunculidae, Pipunculinae) from Iran with four new species records. Journal of Insect

$544 \quad$ Biodiversity and Systematics 03(4): 335-346.

545 Motamedinia B, Skevington JH, Kelso S. 2019. Revision of Claraeola (Diptera, Pipunculidae) in 546 the Middle East based on morphology and DNA barcodes. Zookeys 873: 85-111. doi:

$547 \quad 10.3897 /$ zookeys.873.36645.

548 Perkins RCL. 1905. Leaf-Hoppers and their natural enemies (pt.IV. Pipunculidae). Bulletin

549 Division of Entomology Hawaiian Sugar Planters Association Experiment Station 1:123$550 \quad 157$.

551 Shorthouse DP. 2010. SimpleMappr, an online tool to produce publication-quality point maps. 552 http://www.simplemappr.net.

553 Skevington JH. 2002. Phylogenetic revision of Australian members of the Allomethus genus

554 group (Diptera: Pipunculidae). Insect Systematics and Evolution 33: 133-161.

555 Skevington JH, Kehlmaier C, Ståhls G. 2007. DNA barcoding: Mixed results for big-headed flies 556 (Diptera: Pipunculidae). Zootaxa 1423, 1-26.

557 Skevington JH, Yeates DK. 2001. Phylogenetic classification of Eudorylini (Diptera:

558

Pipunculidae). Systematic Entomology 26: 421-452.

559

560

561 
562 Table 1: Cytochrome c Oxidase I mitochondrial gene primers.

563 Table 2: Uncorrected pairwise distances among Dasydorylas species in the Middle East

564 (intraspecific distances are highlighted in bold).

565

566

Figure 1: Male of Dasydorylas parazardouei Motamedinia \& Skevington sp. nov. (A)

567

habitus in dorsal view (B) compound eyes in dorsal view. Scale bar $=0.25 \mathbf{m m}$.

568

Images by the authors.

569

Figure 2: Male of Dasydorylas discoidalis (A) habitus in dorsal view (B) compound eyes in

570 dorsal view. Scale bar $=0.25 \mathbf{m m}$. Images by the authors.

571

Figure 3: Male genitalia of Dasydorylas discoidalis (A) in dorsal view (B) in ventral view (C,

572

$D)$ in lateral view (E) ejaculatory apodeme. Images by the authors.

573

Figure 4: Male genitalia of Dasydorylas dactylos Motamedinia \& Skevington sp. nov. (A) in

574 dorsal view $(B)$ in ventral view $(C)$ ejaculatory apodeme $(D, E)$ in lateral view.

575 Images by the authors.

576

Figure 5: Male of Dasydorylas horridus (A) habitus in dorsal view (B) thorax and abdomen 577 in dorsal view. Scale bar $=0.25 \mathrm{~mm}$. Images by the authors.

578

579

Figure 6: Male genitalia of Dasydorylas horridus (A) in dorsal view (B) in ventral view (C)

580 Ejaculatory apodeme $(D, E)$ in lateral view. Images by the authors.

Figure 7: Male genitalia of Dasydorylas forcipus Motamedinia \& Skevington sp. nov. (A) in

581

582 dorsal view $(B)$ in ventral view $(C, D)$ in lateral view. Images by the authors.

Figure 8: Male genitalia of Dasydorylas gradus (A) in dorsal view (B) in ventral view (C)

583 ejaculatory apodeme $(D, E)$ in lateral view. Images by the authors.

584

585

586

Figure 9: Male of Dasydorylas forcipus Motamedinia \& Skevington sp. nov. (A) habitus in lateral view (B) hind leg in anterior view. Scale bar $=0.25 \mathrm{~mm}$. Images by the authors.

Figure 10: Male genitalia of Dasydorylas parazardouei Motamedinia \& Skevington sp. nov.

588

589

590

591

592 (A) in dorsal view $(B)$ in ventral view $(C)$ ejaculatory apodeme $(D, E)$ in lateral view. Images by the authors.

Figure 11: Male genitalia of Dasydorylas zardouei (A) in dorsal view (B) in ventral view (C) ejaculatory apodeme (D, E) in lateral view. Images by the authors.

Figure 12: Dasydorylas distribution in the Middle East. 
593 Figure 13: Ovipositor of Dasydorylas parazardouei Motamedinia \& Skevington sp. nov. in 594 lateral view. Scale bar $=0.1 \mathrm{~mm}$. Image by the authors.

595

596

597 


\section{Table 1 (on next page)}

Cytochrome c Oxidase I mitochondrial gene primers. 
1 Table 1: Cytochrome c Oxidase I mitochondrial gene primers.

\begin{tabular}{|c|c|c|c|c|c|c|}
\hline $\begin{array}{l}\text { Gene } \\
\text { name/region }\end{array}$ & $\begin{array}{l}\text { Forward } \\
\text { primer } \\
\text { name }\end{array}$ & $\begin{array}{l}\text { Forward primer } \\
\text { sequence }\left(5^{\prime}-3^{\prime}\right)\end{array}$ & $\begin{array}{l}\text { Primer } \\
\text { reference }\end{array}$ & $\begin{array}{l}\text { Reverse } \\
\text { primer } \\
\text { name }\end{array}$ & $\begin{array}{l}\text { Reverse primer } \\
\text { sequence }\left(5^{\prime}-3^{\prime}\right)\end{array}$ & $\begin{array}{l}\text { Primer } \\
\text { reference }\end{array}$ \\
\hline $\begin{array}{l}\text { COI } \\
\text { Barcode }\end{array}$ & LCO1490 & $\begin{array}{l}\text { GGTCAACA } \\
\text { AATCATAAA } \\
\text { GATATTGG }\end{array}$ & $\begin{array}{l}\text { Folmer } \\
\text { et al. } \\
\text { (1994) }\end{array}$ & $\begin{array}{l}\text { COI- } \\
\text { Dipt- } \\
\text { 2183R }\end{array}$ & $\begin{array}{l}\text { CCAAAAAATC } \\
\text { ARAATARRTG } \\
\text { YTG }\end{array}$ & $\begin{array}{l}\text { Gibson } \\
\text { et al. } \\
(2011)\end{array}$ \\
\hline $\begin{array}{l}\text { COI-Fx-A } \\
\text { (5' end of } \\
\text { barcode) }\end{array}$ & LCO1490 & $\begin{array}{l}\text { GGTCAACA } \\
\text { AATCATAAA } \\
\text { GATATTGG }\end{array}$ & $\begin{array}{l}\text { Folmer } \\
\text { et al. } \\
\text { (1994) }\end{array}$ & $\begin{array}{l}\text { COI- } \\
\text { SYR- } \\
1762 R\end{array}$ & $\begin{array}{l}\text { CGDGGRAAD } \\
\text { GCYATRTCDGG }\end{array}$ & $\begin{array}{l}\text { Young et } \\
\text { al. (in } \\
\text { prep.) }\end{array}$ \\
\hline $\begin{array}{l}\text { COI-Fx-B } \\
\text { (middle of } \\
\text { barcode) }\end{array}$ & $\begin{array}{l}\text { COI- } \\
\text { SYR- } \\
342 F\end{array}$ & $\begin{array}{l}\text { GGDKCHCC } \\
\text { NGAYATRGC }\end{array}$ & $\begin{array}{l}\text { Young et } \\
\text { al. (in } \\
\text { prep.) }\end{array}$ & $\begin{array}{l}\text { COI- } \\
\text { SYR- } \\
1976 R\end{array}$ & $\begin{array}{l}\text { GWAATRAART } \\
\text { TWACDGCHCC }\end{array}$ & $\begin{array}{l}\text { Young et } \\
\text { al. (in } \\
\text { prep.) }\end{array}$ \\
\hline $\begin{array}{l}\text { COI-Fx-C } \\
\text { (3' end of } \\
\text { barcode) }\end{array}$ & $\begin{array}{l}\text { COI- } \\
\text { SYR- } \\
1957 F\end{array}$ & $\begin{array}{l}\text { GGDATWTC } \\
\text { HTCHATYYTAGG }\end{array}$ & $\begin{array}{l}\text { Young et } \\
\text { al. (in } \\
\text { prep.) }\end{array}$ & $\begin{array}{l}\text { COI- } \\
\text { Dipt- } \\
2183 R\end{array}$ & $\begin{array}{l}\text { CCAAAAAATCA } \\
\text { RAATARRTGYTG }\end{array}$ & $\begin{array}{l}\text { Gibson } \\
\text { et al. } \\
(2011)\end{array}$ \\
\hline
\end{tabular}




\section{Table 2 (on next page)}

Uncorrected pairwise distances among Dasydorylas species in the Middle East (intraspecific distances are highlighted in bold). 
1 Table 2: Uncorrected pairwise distances among Dasydorylas species in the Middle East 2 (intraspecific distances are highlighted in bold).

\begin{tabular}{|c|c|c|c|c|c|c|c|c|c|c|c|c|}
\hline & & 1 & 2 & 3 & 4 & 5 & 6 & 7 & 8 & 9 & 10 & 11 \\
\hline 1 & $\begin{array}{c}\text { D. horridus- } \\
\text { JSS52204 }\end{array}$ & & & & & & & & & & & \\
\hline 2 & $\begin{array}{c}\text { D. dactylos- } \\
\text { JSS50777*( } \\
\text { AC) }\end{array}$ & 0.134 & & & & & & & & & & \\
\hline 3 & $\begin{array}{c}D . \\
\text { discoidalis- } \\
\text { JSS52200 }\end{array}$ & 0.151 & 0.099 & & & & & & & & & \\
\hline 4 & $\begin{array}{c}D . \\
\text { discoidalis- } \\
\text { CNCD4706 } \\
32\end{array}$ & 0.142 & 0.086 & 0.013 & & & & & & & & \\
\hline 5 & $\begin{array}{c}D . \\
\text { discoidalis- } \\
\text { CNCD4708 } \\
09\end{array}$ & 0.142 & 0.086 & 0.013 & 0.000 & & & & & & & \\
\hline 6 & $\begin{array}{c}\text { D. gradus- } \\
\text { JSS50850 }\end{array}$ & 0.099 & 0.095 & 0.134 & 0.121 & 0.121 & & & & & & \\
\hline 7 & $\begin{array}{c}\text { D. gradus- } \\
\text { JSS52303 }\end{array}$ & 0.103 & 0.091 & 0.129 & 0.116 & 0.116 & 0.004 & & & & & \\
\hline 8 & $\begin{array}{c}\text { D. gradus- } \\
\text { JSS50771*( } \\
\text { AC) }\end{array}$ & 0.108 & 0.082 & 0.147 & 0.134 & 0.134 & 0.013 & 0.017 & & & & \\
\hline 9 & $\begin{array}{c}D . \\
\text { parazardou } \\
\text { ei- } \\
\text { CNCD1753 } \\
01 *(\mathrm{C})\end{array}$ & 0.142 & 0.147 & 0.168 & 0.168 & 0.168 & 0.112 & 0.108 & 0.099 & & & \\
\hline 10 & $\begin{array}{c}D . \\
\text { parazardou } \\
\text { ei- } \\
\text { CNCD } 1753 \\
03^{*}(\mathrm{C})\end{array}$ & 0.142 & 0.147 & 0.168 & 0.168 & 0.168 & 0.112 & 0.108 & 0.099 & 0.000 & & \\
\hline 11 & $\begin{array}{c}D . \\
\text { discoidalis- } \\
\text { CNCD4706 } \\
47 *(\mathrm{C})\end{array}$ & 0.155 & 0.069 & $\mathbf{0 . 0 3 0}$ & 0.017 & 0.017 & 0.129 & 0.125 & 0.116 & 0.151 & 0.151 & \\
\hline
\end{tabular}

3 * Specimen sequence data was obtained using the COI mini-barcode protocol. A, B, \& C denote the COI mini-barcode regions 4 sequenced. 
Figure 1

Male of Dasydorylas parazardouei Motamedinia \& Skevington sp. nov. (A) habitus in dorsal view (B) compound eyes in dorsal view. Scale bar $=0.25 \mathrm{~mm}$. Images by the authors. 

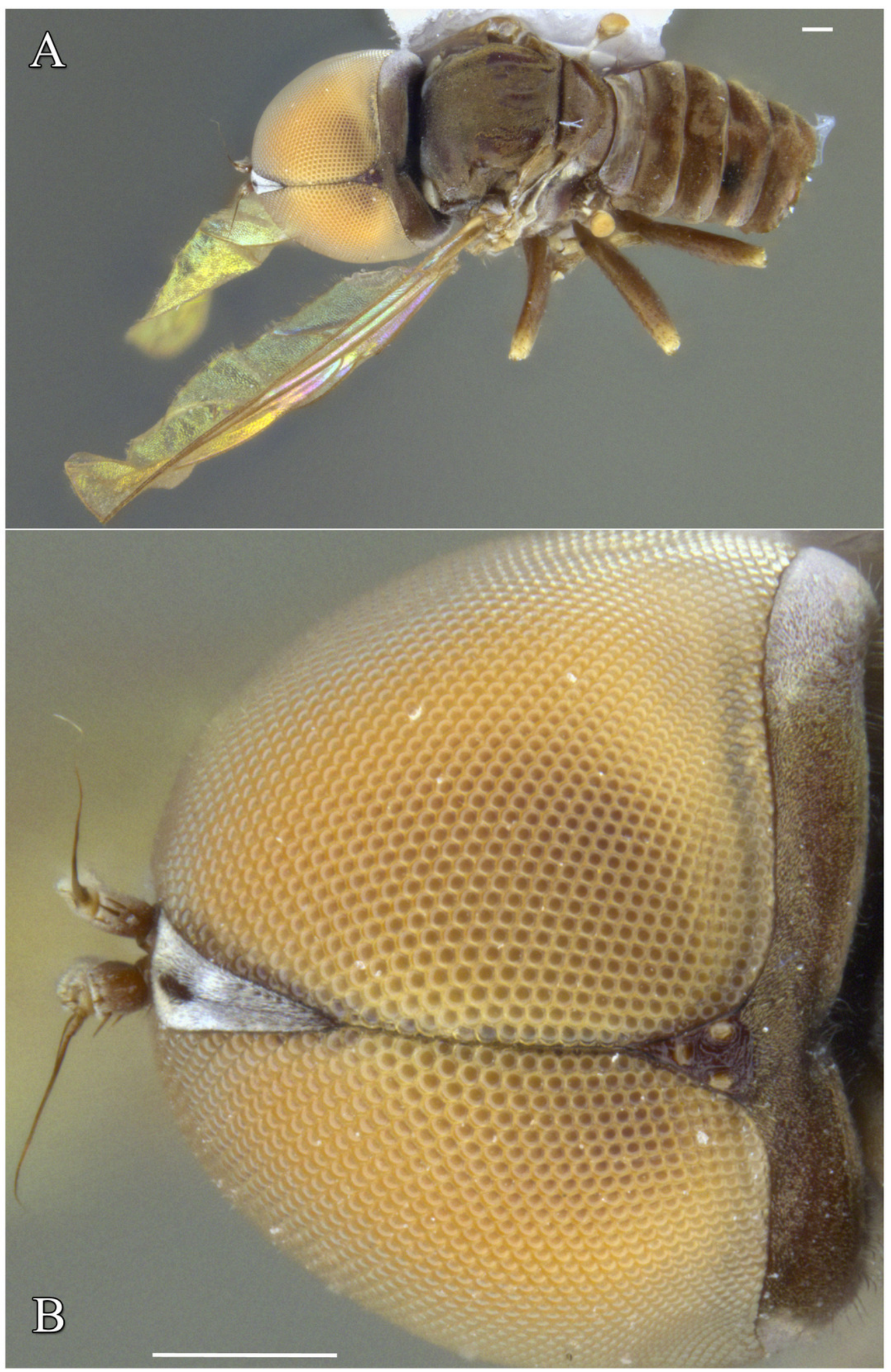
Figure 2

Male of Dasydorylas discoidalis (A) habitus in dorsal view (B) compound eyes in dorsal view. Scale bar $=0.25 \mathrm{~mm}$. Images by the authors. 

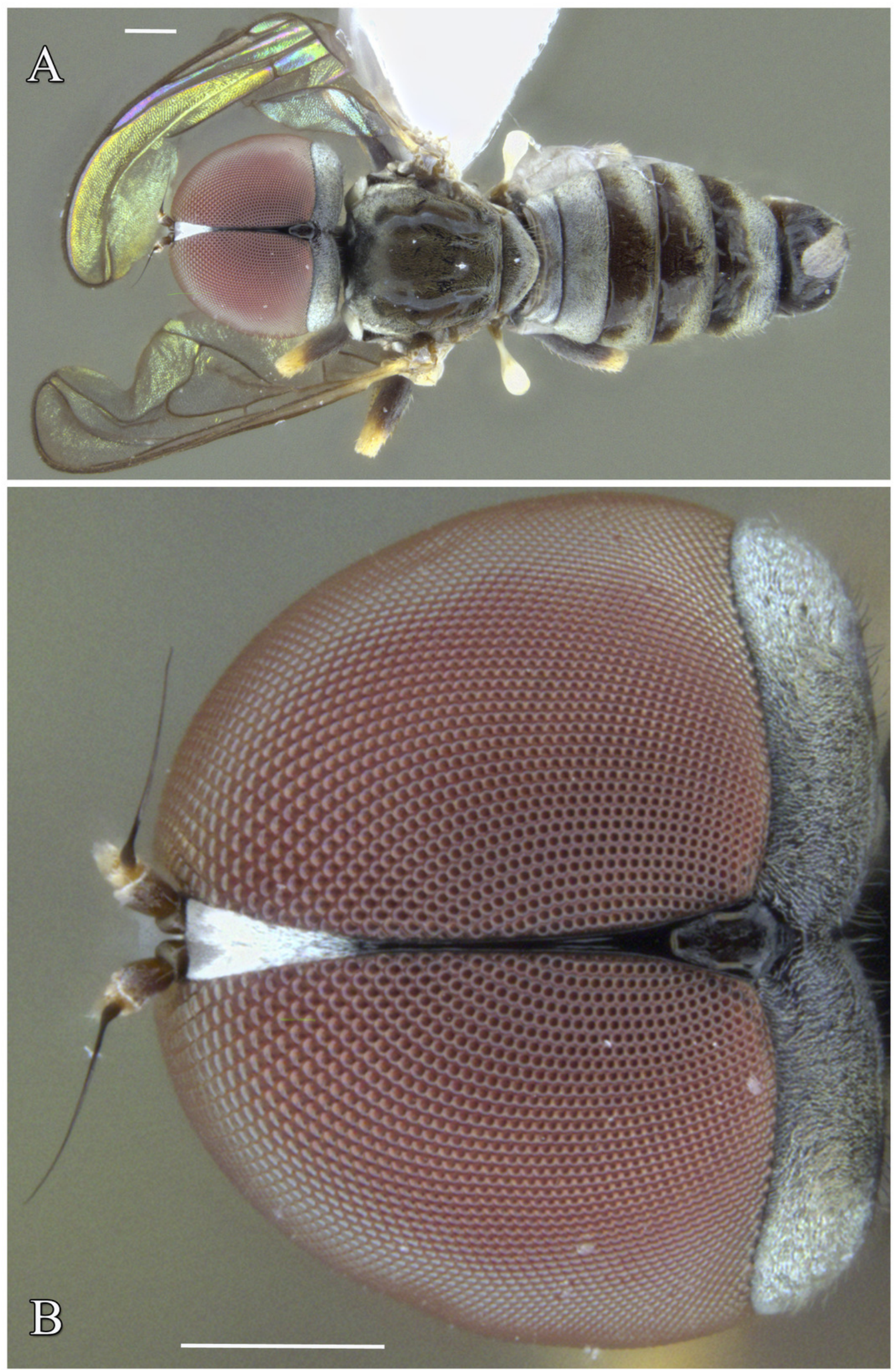
Figure 3

Male genitalia of Dasydorylas discoidalis (A) in dorsal view (B) in ventral view (C, D) in lateral view $(E)$ ejaculatory apodeme. Images by the authors. 

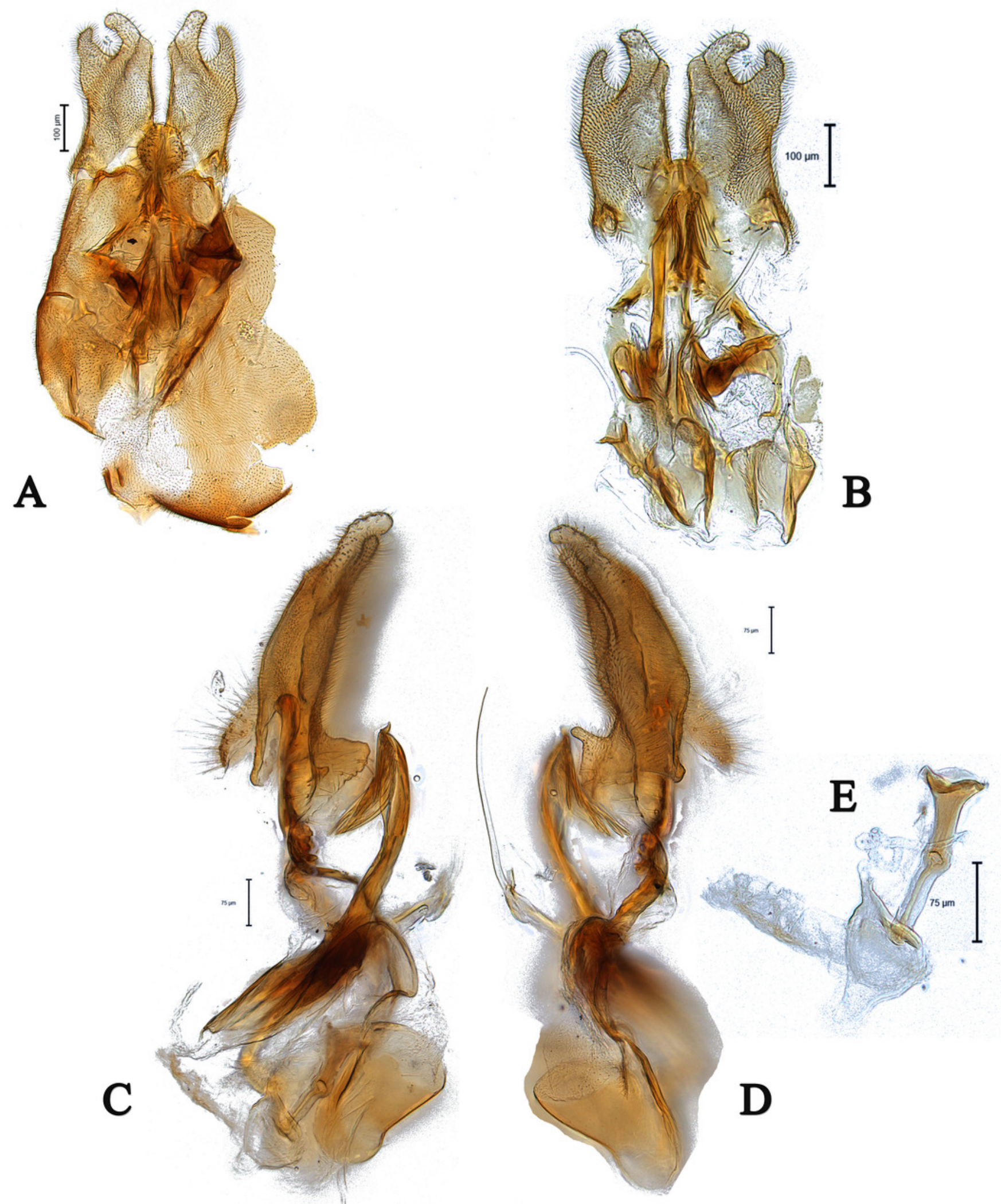
Figure 4

Male genitalia of Dasydorylas dactylos Motamedinia \& Skevington sp. nov. (A) in dorsal view $(B)$ in ventral view $(C)$ ejaculatory apodeme $(D, E)$ in lateral view. Images by the authors. 

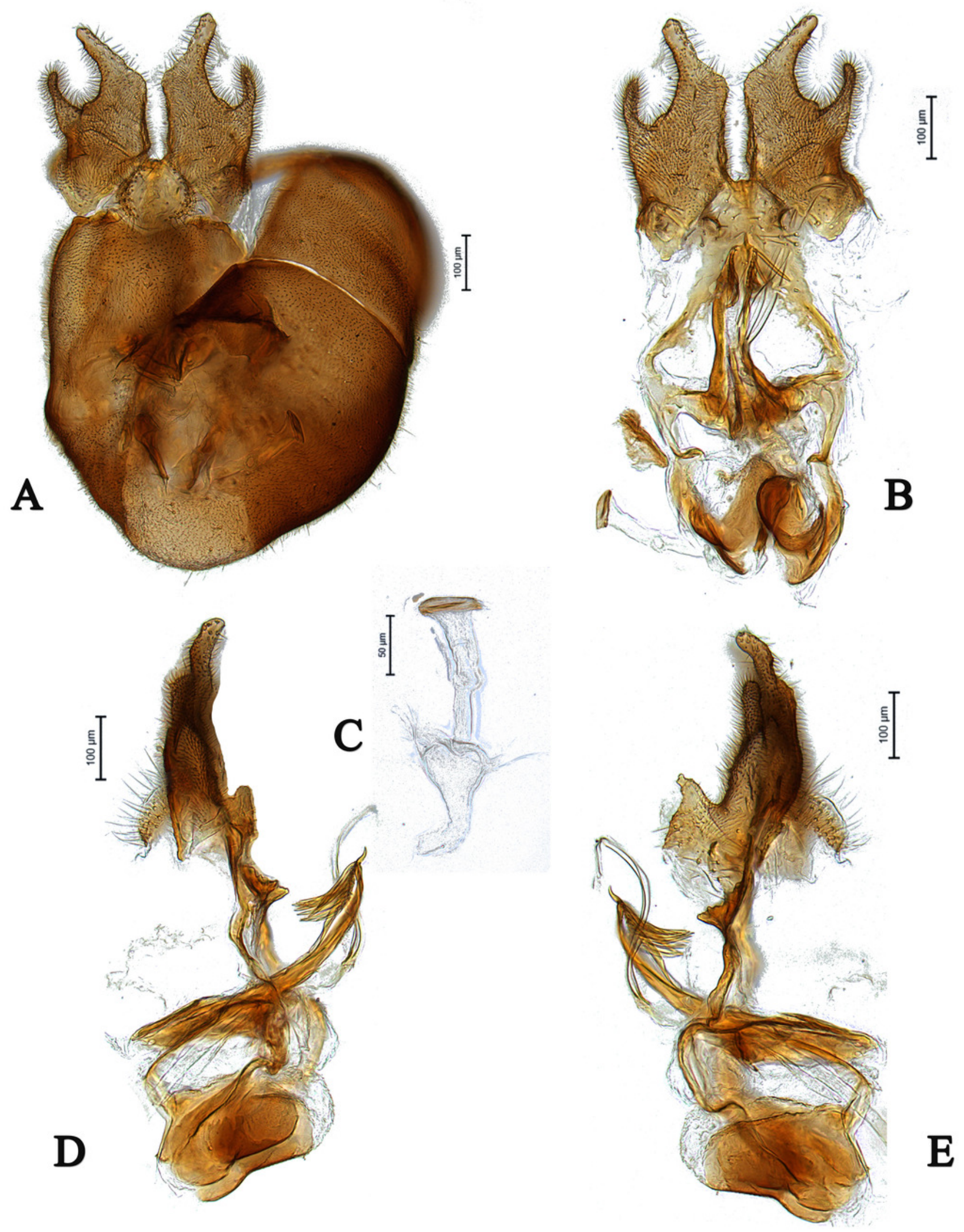
Figure 5

Male of Dasydorylas horridus (A) habitus in dorsal view (B) thorax and abdomen in dorsal view. Scale bar $=0.25 \mathrm{~mm}$. Images by the authors. 

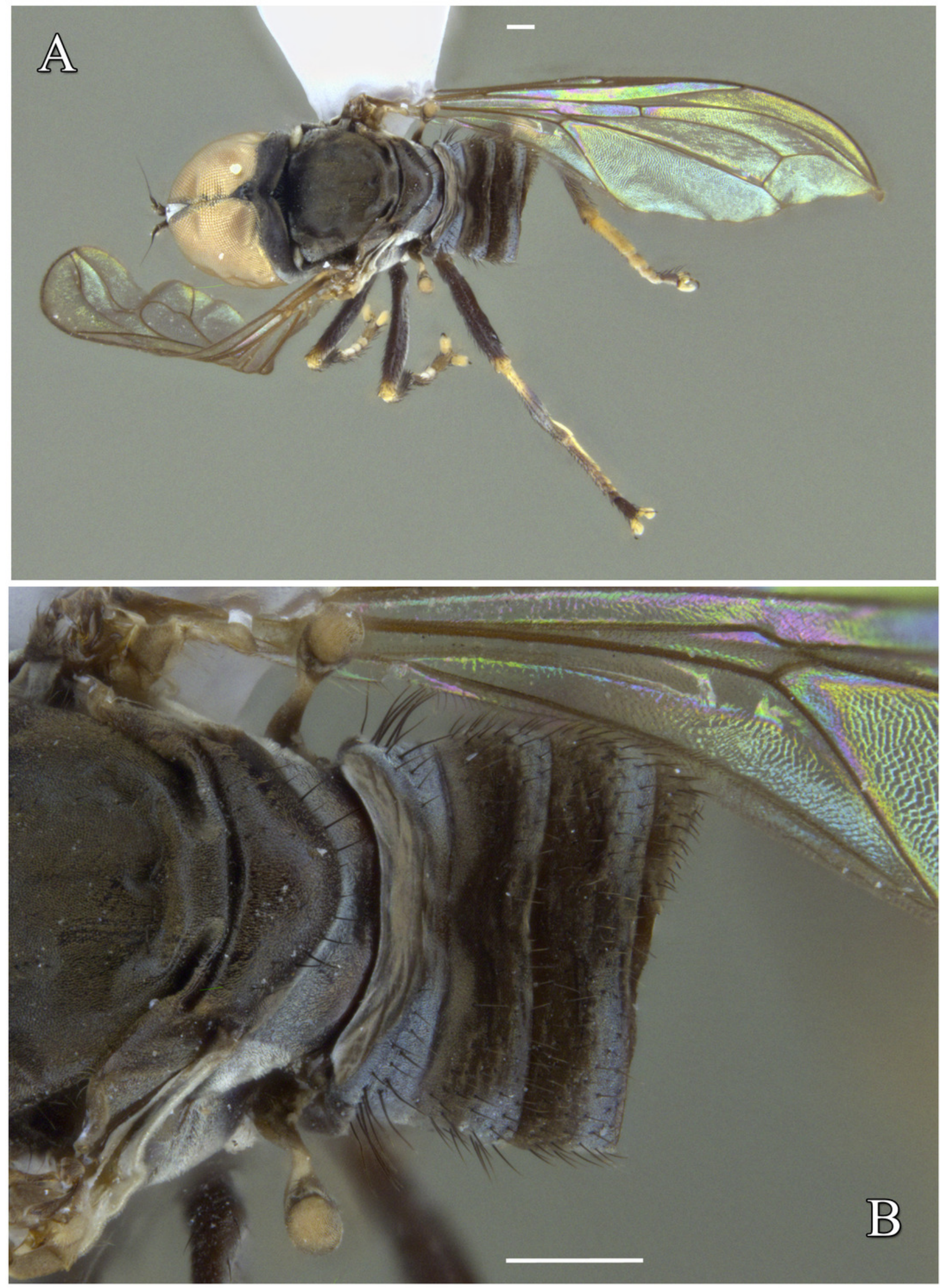
Figure 6

Male genitalia of Dasydorylas horridus (A) in dorsal view (B) in ventral view (C) Ejaculatory apodeme $(D, E)$ in lateral view. Images by the authors. 

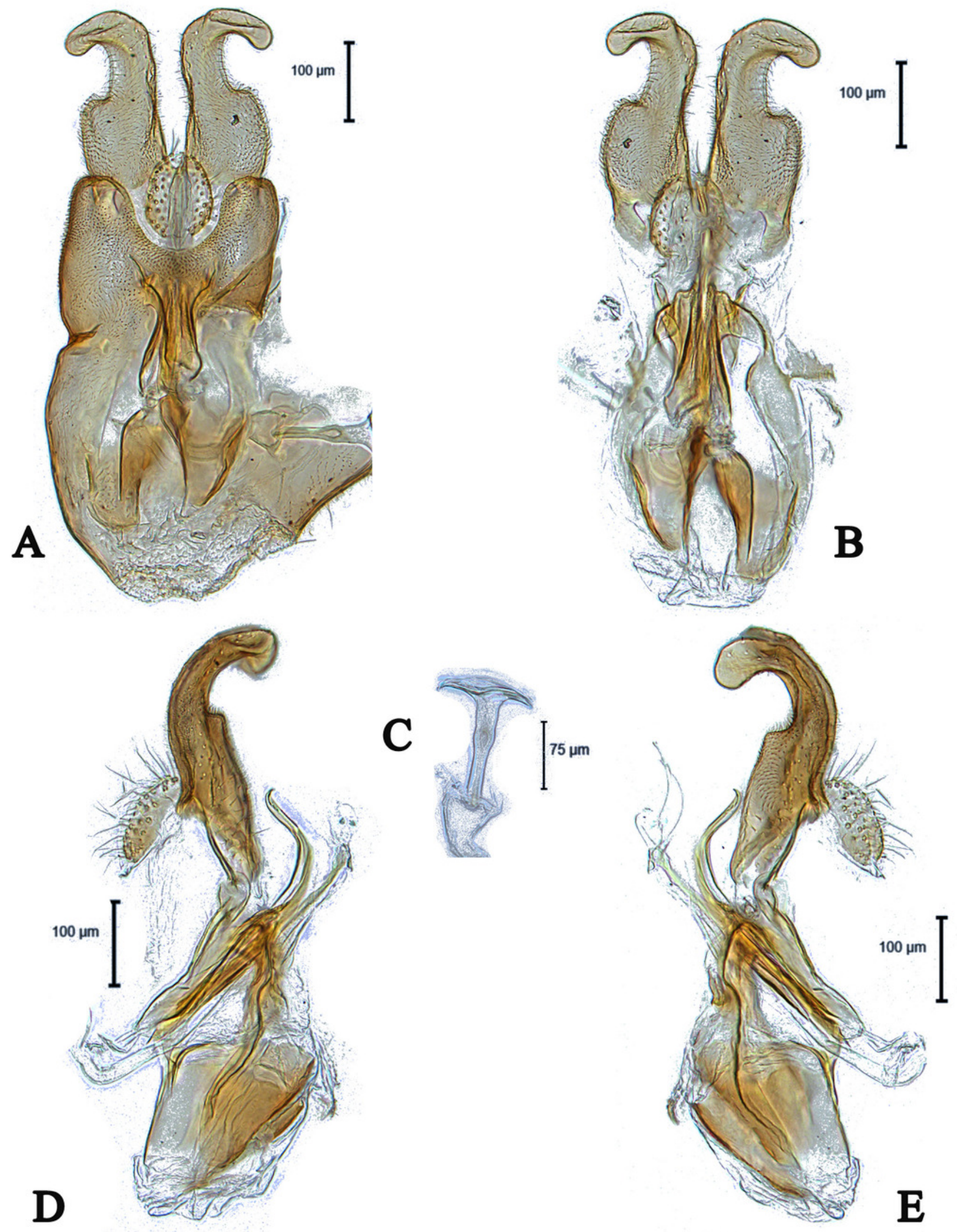
Figure 7

Male genitalia of Dasydorylas forcipus Motamedinia \& Skevington sp. nov. (A) in dorsal view $(B)$ in ventral view $(C, D)$ in lateral view. 

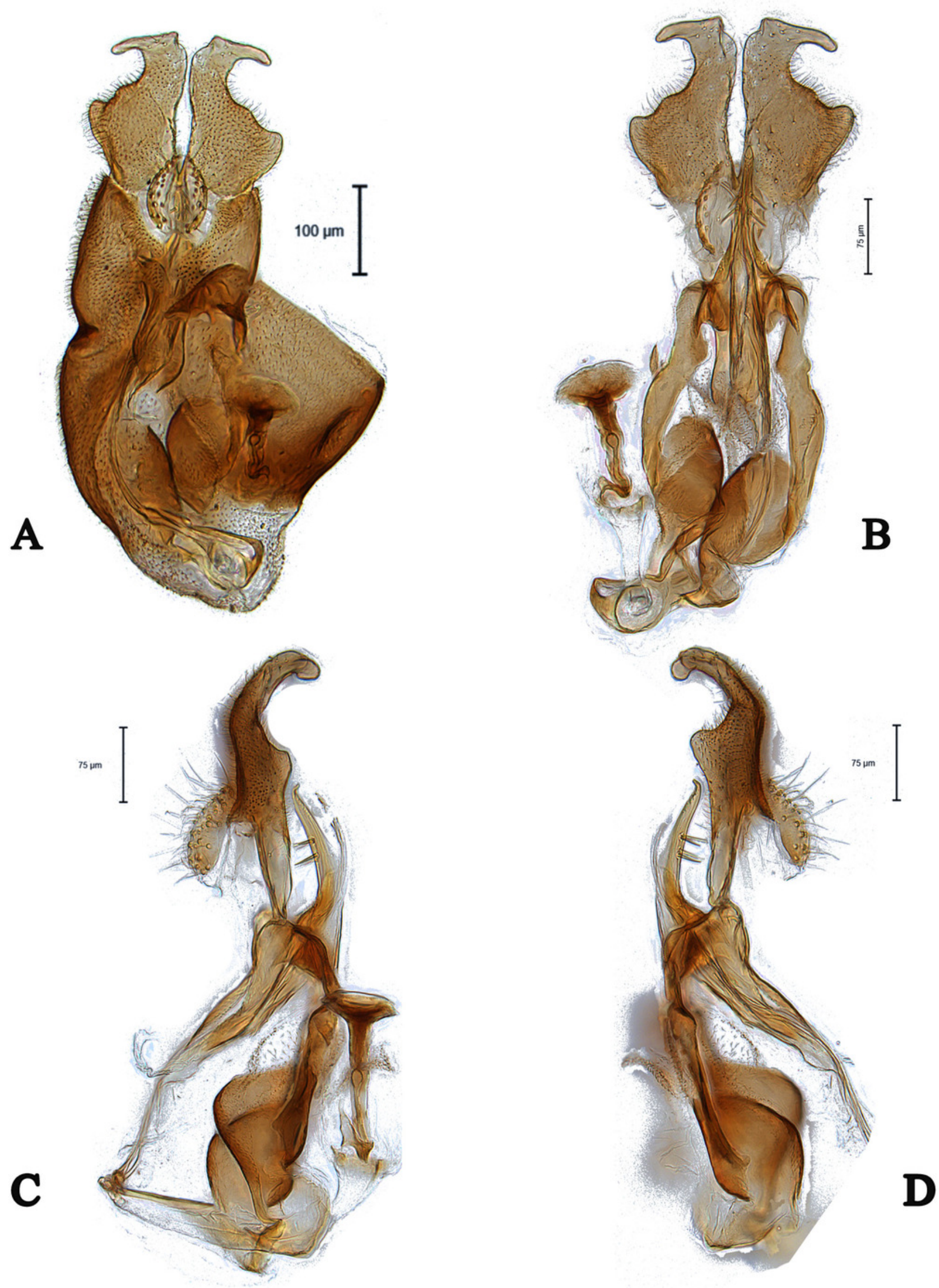
Figure 8

Male genitalia of Dasydorylas gradus (A) in dorsal view (B) in ventral view (C) ejaculatory apodeme (D, E) in lateral view. 

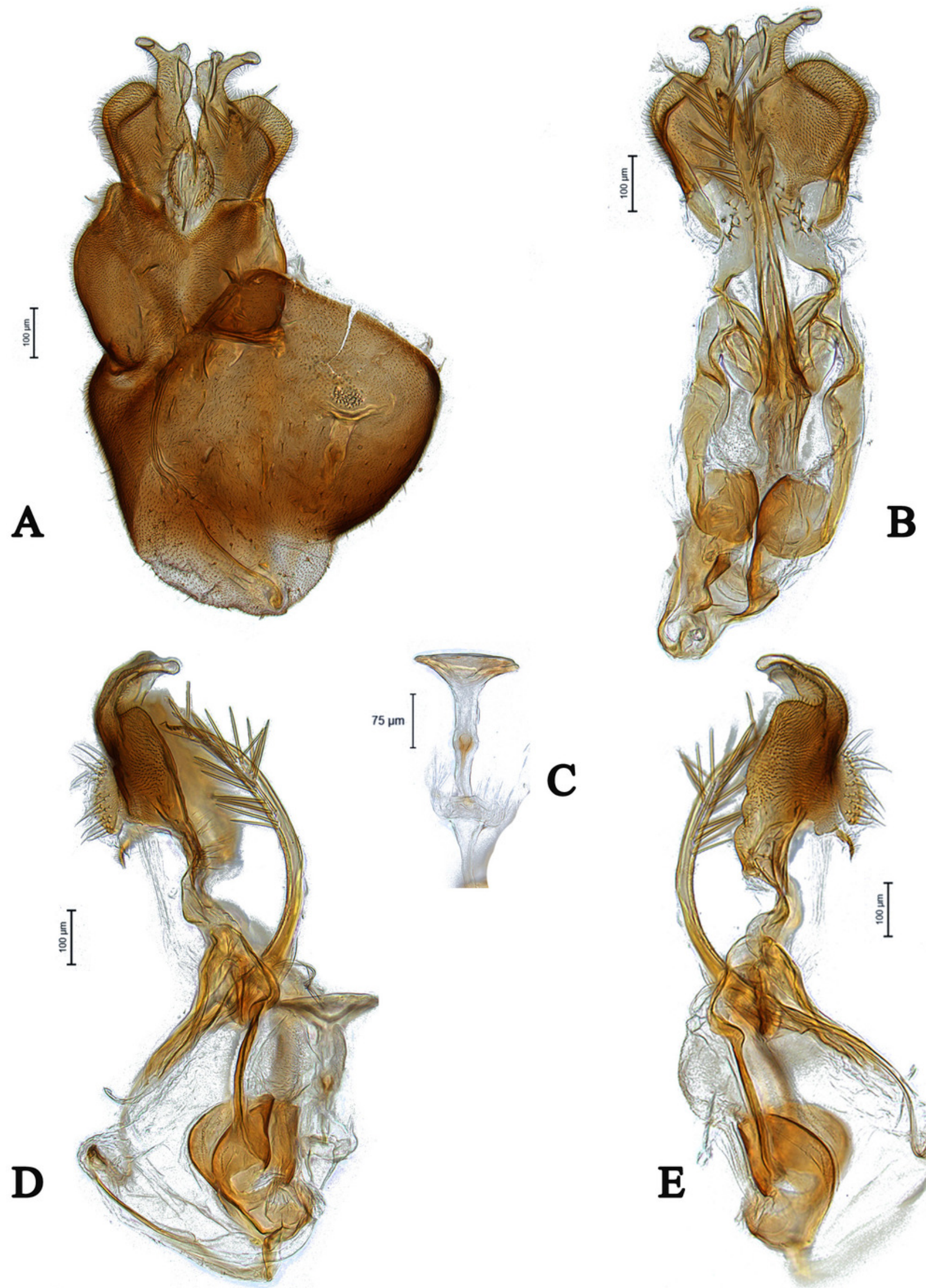
Figure 9

Male of Dasydorylas forcipus Motamedinia \& Skevington sp. nov. (A) habitus in lateral view (B) hind leg in anterior view. Scale bar $=0.25 \mathrm{~mm}$. 

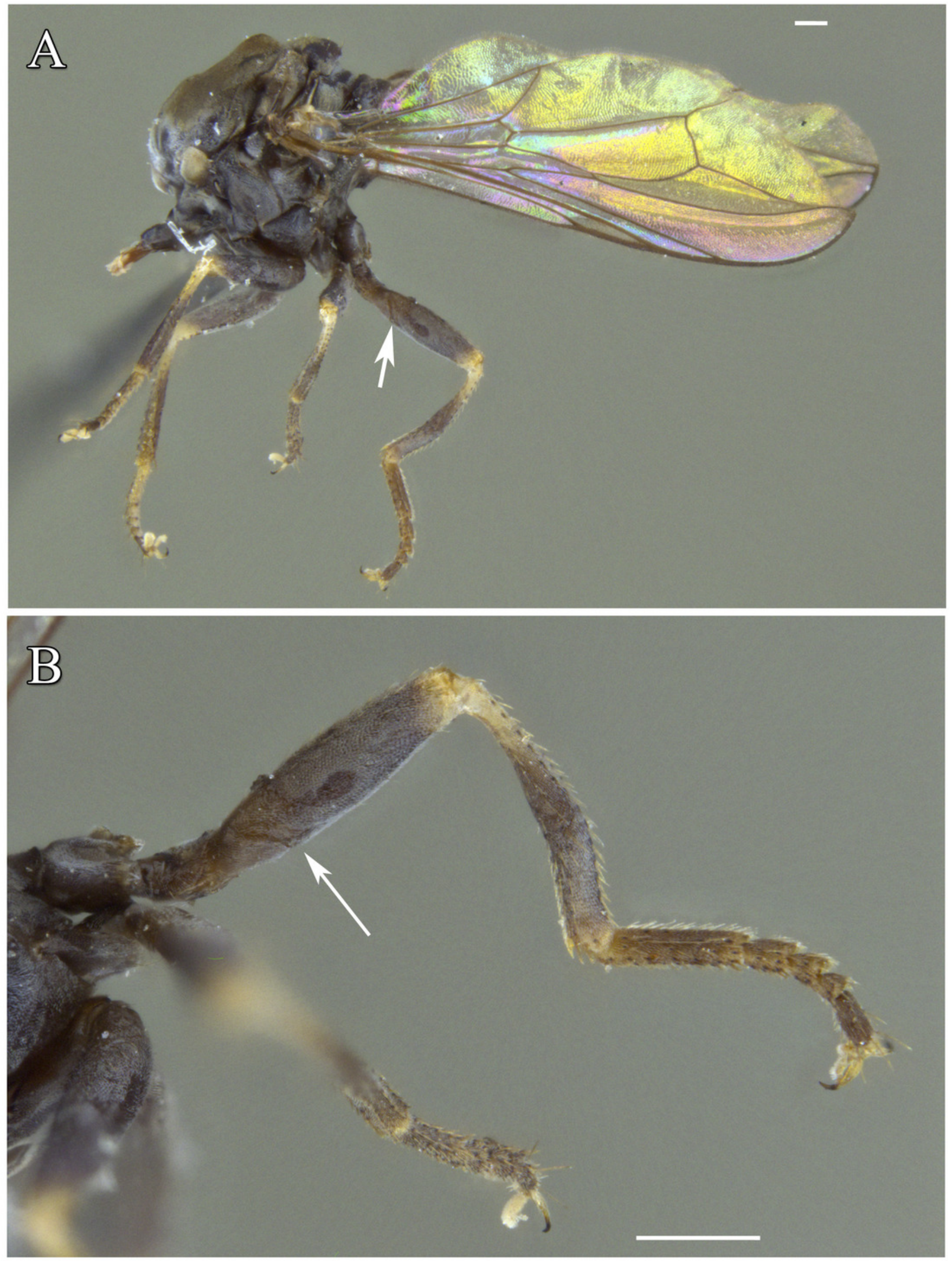
Figure 10

Male genitalia of Dasydorylas parazardouei Motamedinia \& Skevington sp. nov. (A) in dorsal view (B) in ventral view (C) ejaculatory apodeme (D, E) in lateral view. 

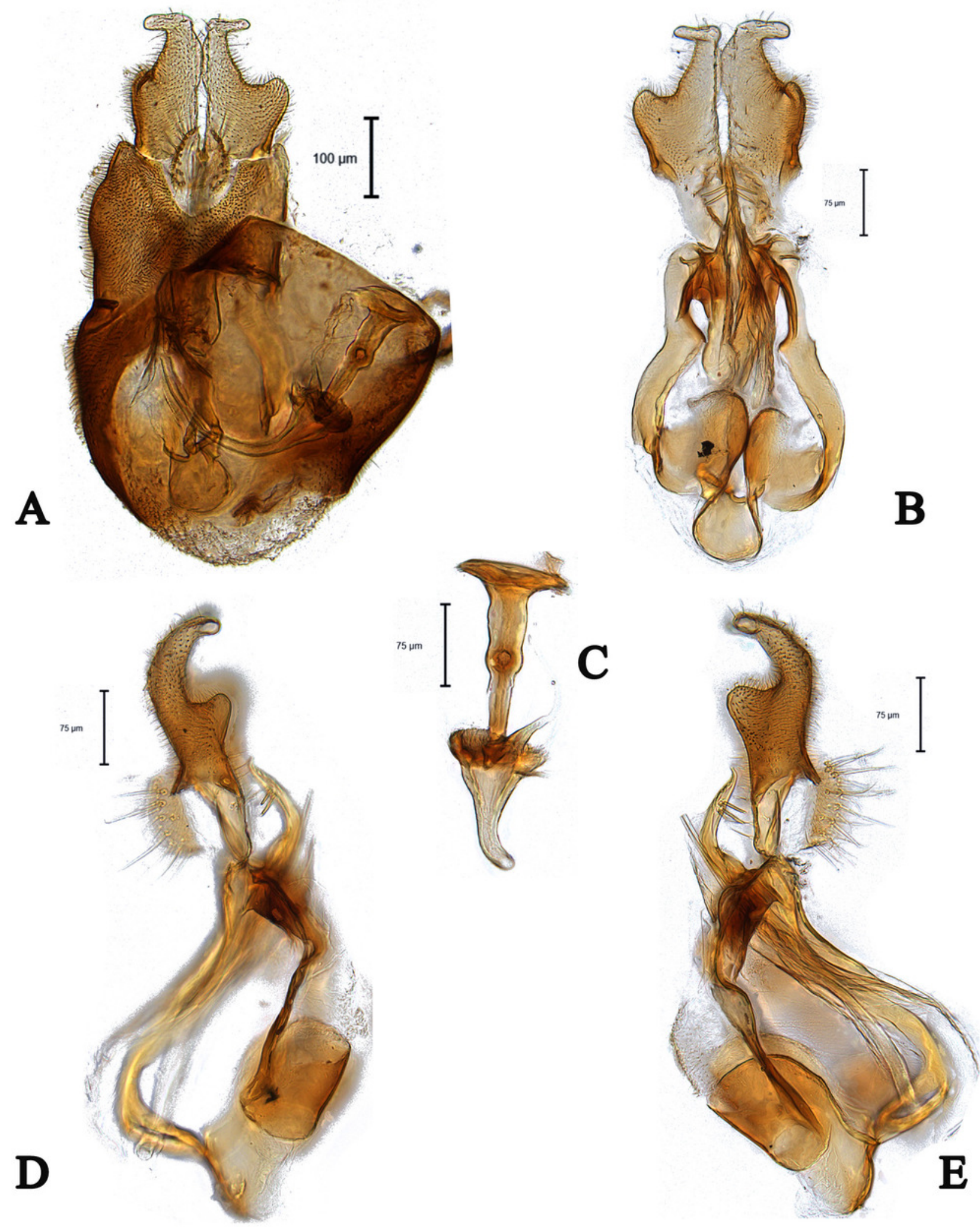
Figure 11

Male genitalia of Dasydorylas zardouei (A) in dorsal view (B) in ventral view (C) ejaculatory apodeme (D, E) in lateral view. 

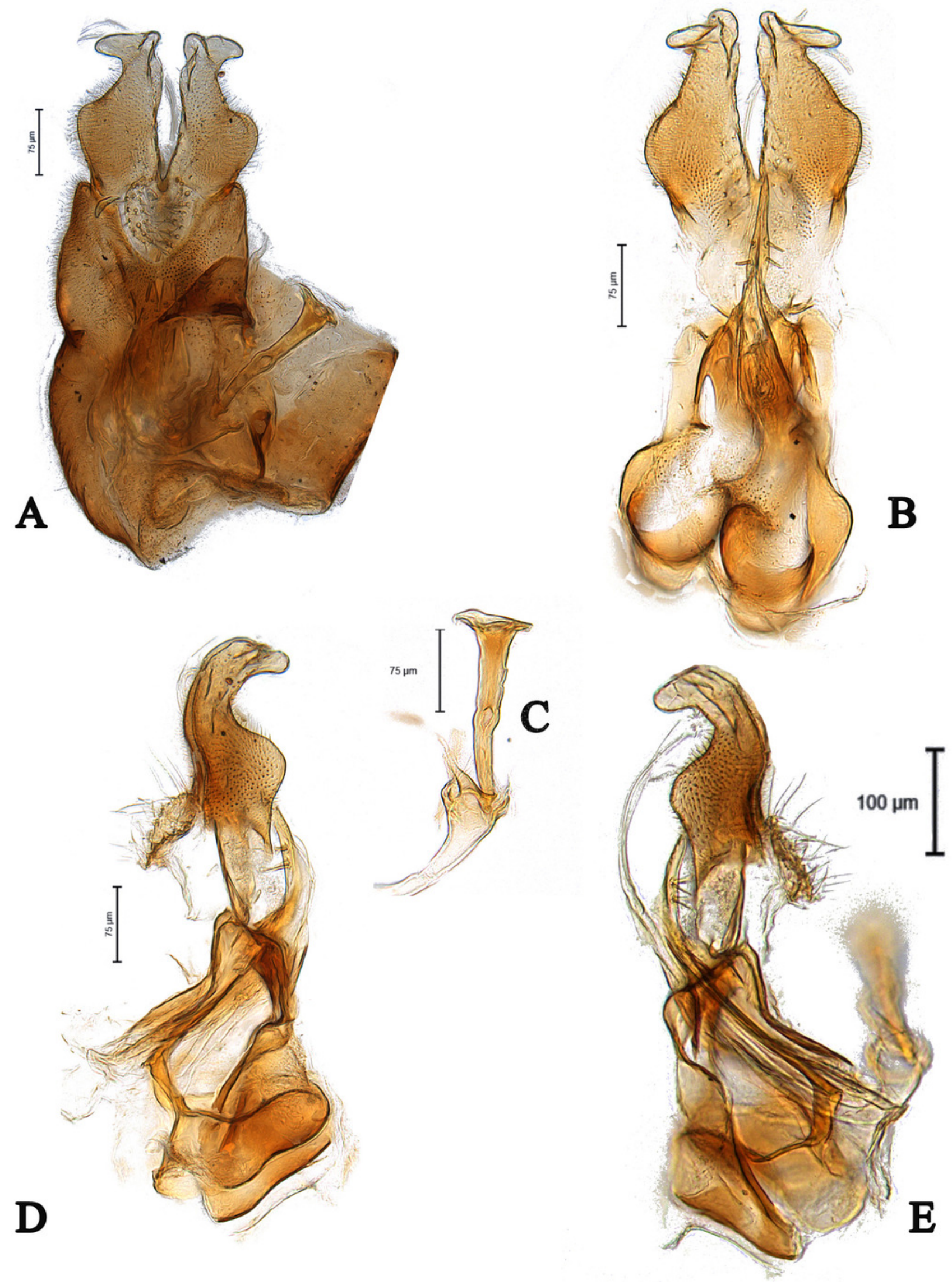
Figure 12

Dasydorylas distribution in the Middle East.

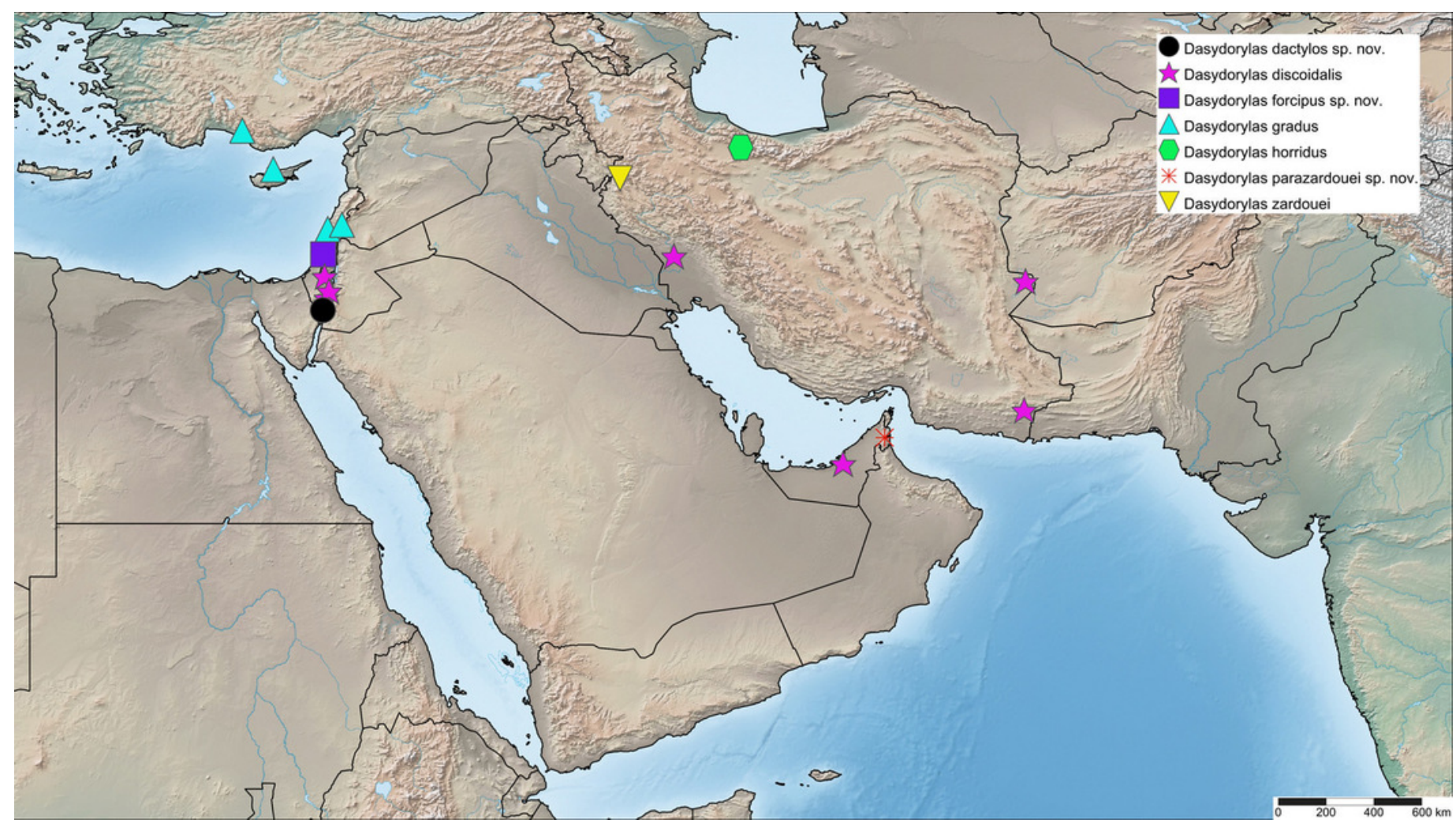




\section{Figure 13}

Ovipositor of Dasydorylas parazardouei Motamedinia \& Skevington sp. nov. in lateral view. Scale bar $=0.1 \mathrm{~mm}$.

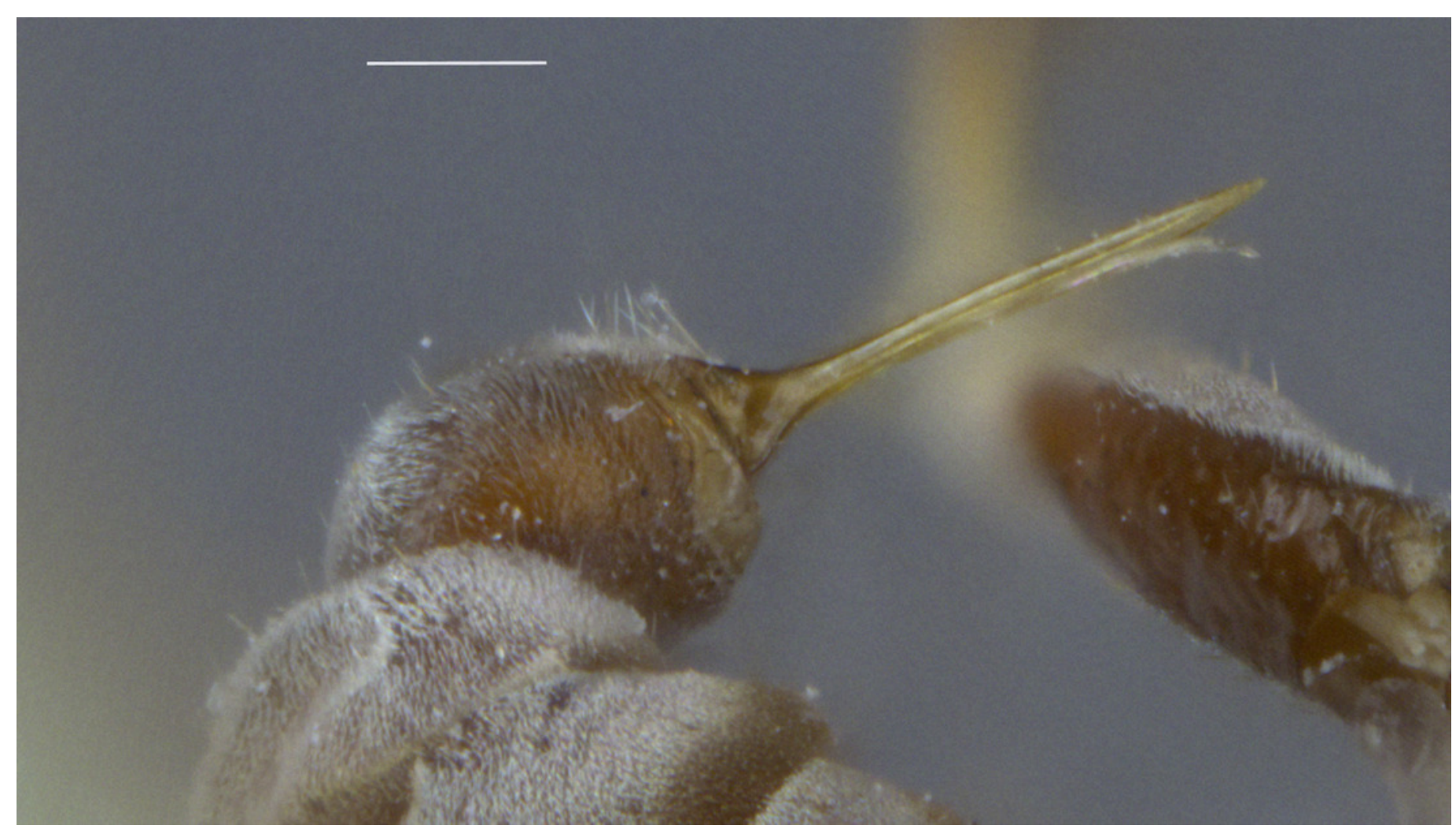

